\title{
Saving energy in China's industry with a focus on electricity: a review of opportunities, potentials and environmental benefits
}

\author{
Hui Yue $\cdot$ Ernst Worrell $\cdot$ Wina Crijns-Graus • \\ Wen Liu $\cdot$ Shaohui Zhang
}

Received: 20 May 2020 / Accepted: 8 July 2021 /Published online: 28 July 2021

(C) The Author(s) 2021

\begin{abstract}
Industry is the largest electricity consuming sector in the world. China consumes about $25 \%$ of global electricity demand, and $69 \%$ of this is used in industries. The high electricity demand in industry is responsible for $45 \%$ of $\mathrm{CO}_{2}, 25 \%$ of $\mathrm{SO}_{2}, 34 \%$ of $\mathrm{NO}_{\mathrm{x}}$ and $14 \%$ of PM emissions in China. This study aims to fill the knowledge gap on the potential for electricity savings in China's industries, thereby providing important implications for the potential of
\end{abstract}

Supplementary Information The online version contains supplementary material available at https://doi. org/10.1007/s12053-021-09979-4.

H. Yue $(\varangle) \cdot$ E. Worrell $(\square) \cdot$ W. Crijns-Graus · W. Liu Copernicus Institute of Sustainable Development, Utrecht University, Princetonlaan 8a, 3584 CB Utrecht, The Netherlands e-mail: H.Yue@uu.nl

E. Worrell

e-mail: E.Worrell@uu.nl

W. Crijns-Graus

e-mail: W.H.J.Graus@uu.nl

W. Liu

e-mail:W.Liu@uu.nl

S. Zhang

School of Economics and Management, Beihang University, 37 Xueyuan Road, Beijing 100191, China e-mail: S_Zhang@buaa.edu.cn

\section{S. Zhang}

International Institute for Applied Systems Analysis,

Schlossplatz 1, 2361 Laxenburg, Austria reducing emissions in electricity-intensive industrial subsectors in general. Available studies are reviewed and compared to identify electricity-saving potentials. The findings show that China's industrial energy system is shifting to higher electricity and relatively lower fossil fuel use due to accelerated end-use electrification. China's industry can reduce electricity use by $7-24 \%$ in 2040 , compared to baseline levels, and generate emission reductions of $192-1118 \mathrm{Mt}-\mathrm{CO}_{2}$, 385-2241 kt-SO ${ }_{2}, 406-2362 \mathrm{kt}-\mathrm{NO}_{\mathrm{x}}$ and 92-534 $\mathrm{kt}-\mathrm{PM}_{2.5}$. The iron \& steel subsector has the largest contribution to the industrial electricity savings, followed by non-ferrous metals, chemicals, cement and pulp \& paper. Policies that combine environmental targets, demand-side efficiency and supply-side retrofits in the power sector should be adopted. Given the different performance of policies in terms of energy savings and emission reduction, sector- and regionspecific policies would be preferred.

Keywords Energy efficiency · Electricity saving · Industry $\cdot$ Air pollutants $\cdot$ Carbon emissions $\cdot$ China

\section{Introduction}

Since 1990, global electricity demand has more than doubled (from $9700 \mathrm{TWh}$ in 1990 to 20,900 TWh in 2016), with a growth rate of $3.4 \%$ per year (IEA, 2018). In 2016, $38 \%$ of global electricity use was generated by coal, $23 \%$ by natural gas, $17 \%$ by hydro, 
$10 \%$ by nuclear, $8 \%$ by renewables and the remaining $4 \%$ by oil (IEA, 2018). The high share of fossil fuels makes the power sector one of the largest emitters of greenhouse gases (GHGs) and air pollutants. In 2016, $41 \%$ of $\mathrm{CO}_{2}$ emissions, $36 \%$ of $\mathrm{SO}_{2}$ emissions, $15 \%$ of $\mathrm{NO}_{\mathrm{x}}$ emissions, $6 \%$ of $\mathrm{PM}_{2.5}$ emissions around the world are produced by electricity generation (IEA, 2016b). It is expected that global power consumption will keep growing over the next decades due to the acceleration of industrialization and electrification in developing economies. As a major source of GHG emissions, many countries are making great efforts to decarbonize their power supply. Besides climate change, health impacts of air pollution are of great attention. An estimate by the World Health Organization shows that 4.2 million premature deaths globally are attributable to air pollution in 2016 (WHO, 2018). Improving energy efficiency in end-use sectors would therefore generate multiple benefits, by reducing both types of emissions, as well as limiting the needs for investments in new power capacities and grid extensions.

Industrial processes are responsible for $42 \%$ of global electricity demand in 2016 (IEA, 2018). This makes the industry sector an attractive target for reducing emissions through the efficient use of electricity. This study focuses on electricity conservation in industrial sectors by performing an in-depth review of available literature on the most consuming subsectors and key energy-saving technologies, taking the largest electricity consumer, China, as case. China consumes $25 \%$ of global electricity demand, which is double the total consumption of the European Union, and $69 \%$ of the national electricity consumption is used by the industrial sector, in 2016 (Fig. 1).

As a large manufacturing country of energyintensive products, China also leads the electricity consumption at the subsector level (followed by the USA, Russia, India, respectively), accounting for around $50 \%$ of global electricity consumption per industrial subsector (Fig. 1). The high electricity demand increases air pollutants from the power sector in China, for example, around $27.2 \%$ of $\mathrm{SO}_{2}$ emission, $26.9 \%$ of $\mathrm{NO}_{\mathrm{x}}$ emission and $14.8 \%$ of $\mathrm{PM}$ are caused by power generation (NBS and MEP 2018). Annually, more than 1 million people die prematurely in China as a result of exposure to high concentrations of PM, of which power generation is estimated to contribute to $39 \%$ of mortality (Gao et al., 2018).
While the annual concentration of $\mathrm{PM}_{2.5}$ and $\mathrm{PM}_{10}$ decreased by $5.4 \%$ and $1.9 \%$ in 2017 (Huang et al., 2018), respectively, compared to 2016 levels, concentrations are still higher than the Chinese national level II targets $\left(\mathrm{PM}_{2.5}\right.$ of $35 \mu \mathrm{g} / \mathrm{m}^{3}$ and $\mathrm{PM}_{10}$ of $\left.70 \mu \mathrm{g} / \mathrm{m}^{3}\right)$ (MEP and AQSIQ 2016), stressing the need for future emission reductions. The high electricity demand delivered by a coal-dominated power generation sector, and its contribution to poor air quality require integrated approaches to help improve air quality. The Chinese government is taking serious efforts to control emissions of air pollutants by requiring more strict emission standards for energy-intensive sectors (e.g. cement, chemical and iron \& steel) (MEP \& AQSIQ 2019), retiring small coal-fired power units (NDRC, 2019) and limiting energy consumption per unit product (e.g. primary aluminum and crude steel) (MIIT, 2017). Furthermore, China is also under huge pressure to reduce GHG emissions and has committed to cutting its carbon intensity by 60 to $65 \%$ by 2030 from a 2005 baseline, peaking GHG emissions by 2030 . About $45 \%$ of $\mathrm{CO}_{2}$ emissions from China's industrial sector can be attributed to electricity consumption, reaching $2690 \mathrm{Mt}-\mathrm{CO}_{2 \text { eq }}$ in 2015 (CEADs, 2017). Promoting electricity conservation is an effective way to both reduce overall emissions of GHG and air pollutants from coal-fired power generation, offering synergies for electricity intensity, air quality (Yue et al., 2018), climate change (IRENA, 2017) and health effects from ambient air pollution (Abel et al., 2019), as well as economic benefits (U.S. EPA 2015).

Although studies have looked previously at energy efficiency (Karali et al., 2020; Zhang et al., 2020) and emission reduction (Khanna et al., 2019; Zhou et al., 2018a) in China, a comprehensive understanding of electricity use and conservation in China's industry perspective is still lacking. Most studies have focused on direct fuel use in end-use sectors, as fuel demand is still larger and contributes to direct emissions of the end-use sectors. Moreover, the studies on electricity often take a top-down view on electricity demand, without sufficient detail on the electricity end-uses and subsectors. To fill this gap, this study provides an industry-wide overview of electricitysaving potentials in China, based on available studies, and estimates associated benefits on emission reduction potentials. China can be a great case bringing guidance for countries dominated with industry and coal power (e.g. Australia, India, Mongolia, South 


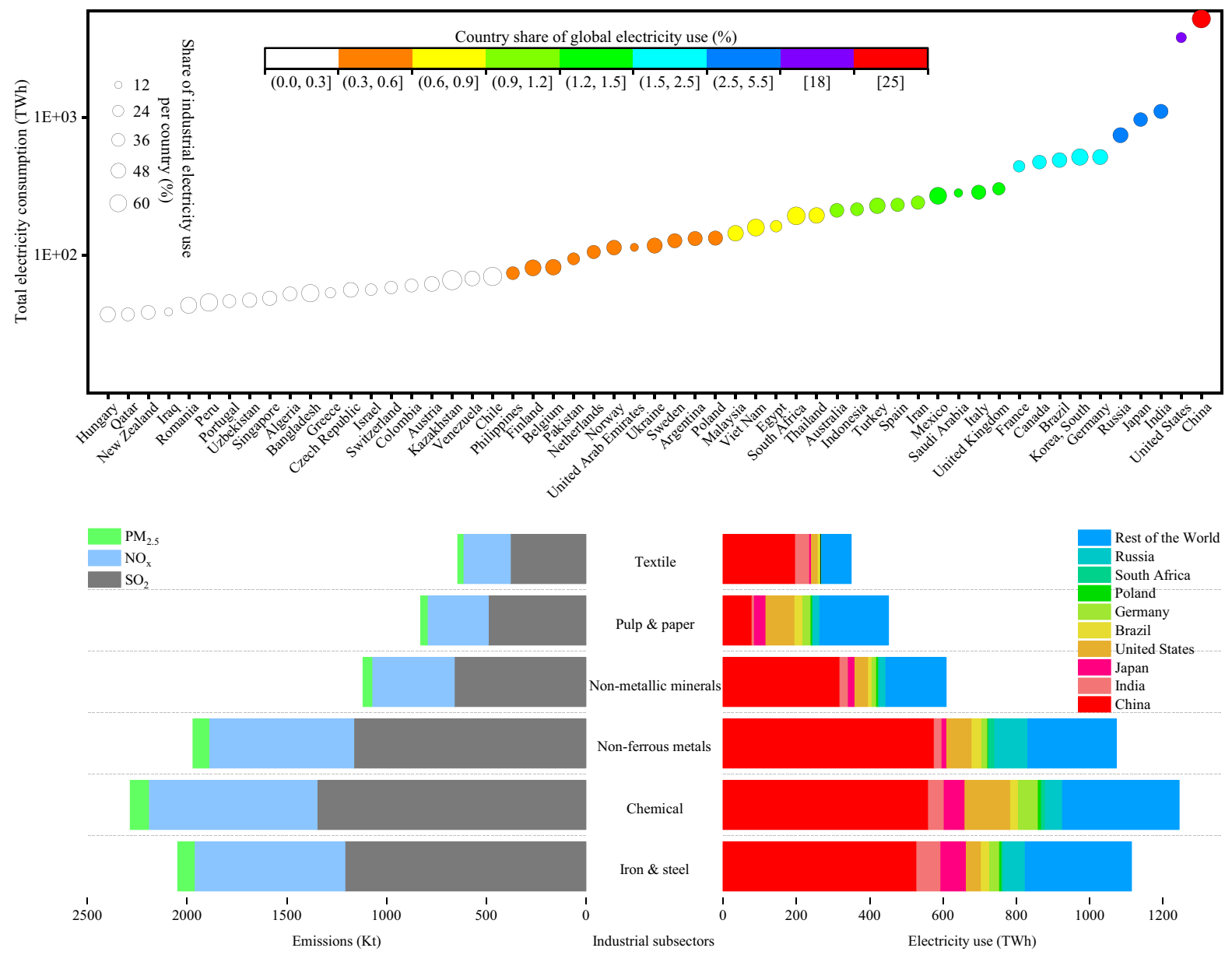

Fig. 1 Electricity consumption levels, and sectoral emission levels due to electricity use. Source: primary data from World Energy Balances (IEA, 2018) and China Energy Statistical

Africa and Poland) in saving energy, cleaning up air and mitigating climate change. Within industry, five energy-intensive subsectors (i.e. iron \& steel, cement, non-ferrous metals, pulp \& paper and chemical) together account for $65 \%$ of China's industrial energy consumption $^{1}$ and are analyzed in-depth in this study. These industries are also highlighted by the IEA (IEA, 2016a, 2017), EIA (EIA, 2018) and China's development plan for energy conservation and emission reduction (State Council of China, 2017). The five energy-intensive subsectors are complemented

\footnotetext{
1 The five subsectors are electricity-intensive end-use sectors, which together accounted for around 50\% of China's industrial electricity consumption.
}

Yearbook (NBS 2017). Calculated by authors. Note: the y-axis in the Bubble plot represents a logarithmic scale

by the textile industry, which is a non-energy-intensive industry, but a large electricity consumer. This review-based research provides important insights in the way forward for reducing electricity-derived emissions in the industry for the most polluting countries, with an in-depth focus on the big contributing subsectors and key manufacturing processes.

Specifically, the main contribution of this study is answering the following four questions. (1) How much electricity can China's industry save? (2) Which industrial subsectors have the highest potentials of electricity savings and associated emission reduction? (3) Which research fields should be given more attention? (4) How to design and implement (industrial energy) policies to jointly achieve electricity, climate 


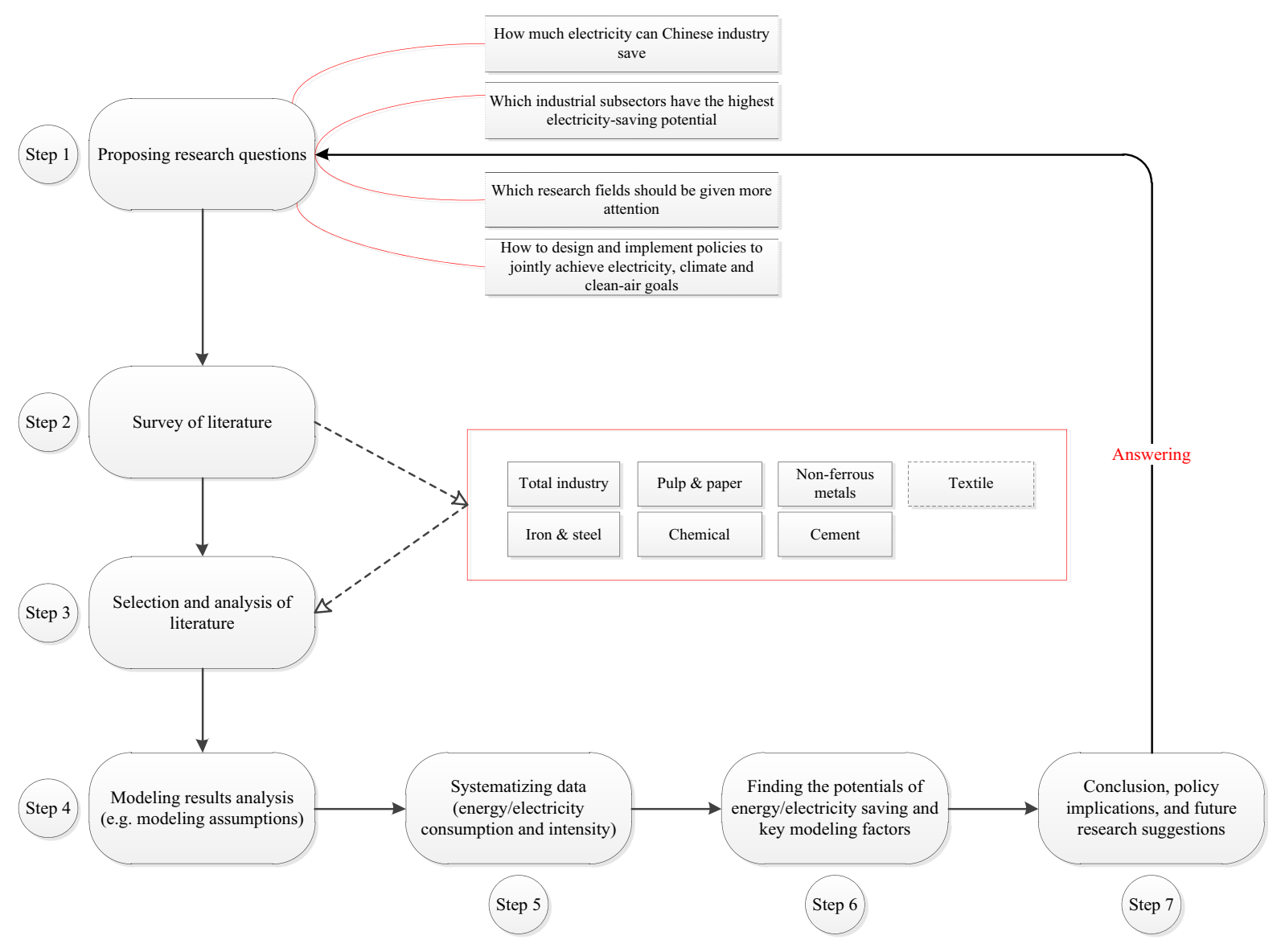

Fig. 2 Methodological steps

and clean-air goals (at national, regional and sectoral levels)? The study presents the available literature and classified these studies by industrial subsectors in Section 2 and 3 discusses the methodological differences between the studies. The main results, in terms of electricity-saving potentials and associated environmental benefits in China's industrial sectors are presented in Section 4. Finally, conclusions and policy implications are given in Section 5 and 6 , respectively.

\section{Methodology}

Review method

A systematic review method is carried out to address the questions in this study, consisting of seven steps (Fig. 2). In the first step, four questions are proposed related to the knowledge gap on understanding the role and potential of electricity savings for reducing air emissions in industry. In the second step, targeted keywords are used, combined with the snowballing technique to identify relevant publications from various databases (e.g. Google Scholar, Web of Science and Scopus). Keywords reflecting the study purpose include "electricity saving", "energy saving", "efficiency" and "China's industry". Snowballing was used to check for additional publications in the reference list of the identified papers and for studies that cited the identified papers. During the third step, the available publications are analyzed to discuss their main characteristics (in Section 2). The selected studies allowed obtaining relevant data to be analyzed. In the fourth step, the methodological differences between the studies are discussed to be able to interpret the modeling results (Section 3). In the fifth and sixth steps, the collected data on energy consumption 
and intensity from the studies are systematically processed to estimate the electricity-saving potentials (Section 4). The framework is completed in the seventh step, highlighting the role of electricity as a key energy carrier and identifying the highest potential subsectors (Section 5). Furthermore, suggestions on joint policy design and further research are provided in the seventh step (Section 6).

\section{Literature selection}

Table 1 gives an overview of studies that focused on energy-saving potentials in China's industrial subsectors (i.e. iron \& steel, cement, non-ferrous, pulp \& paper and chemical sectors), including some of their key characteristics (such as studied period, model used and research scope). A discussion on the literature review of energy-saving potentials in China's industry is given below and is structured by subsector, ${ }^{2}$ starting with studies that focus on industry as a whole.

China's industry Limited studies were found that evaluate the future potentials of China's entire industry with detailed subsector information. The study of Ouyang and Lin (2015) analyzed the driving forces of energy-related $\mathrm{CO}_{2}$ emissions in China's industry and suggested that energy efficiency improvement through efficient technology promotion and phasing out of inefficient production capacities was a major cause of $\mathrm{CO}_{2}$ emission reduction in the period 1991-2010. Another study of Meng et al. (2014) analyzed the electricity-saving potentials of 20 economic sectors in China and showed that the chemical and mechanical sectors have large potentials for electricity efficiency improvement. These studies emphasize the considerable energy-saving potentials in China's industry and indicate energy efficiency improvement is key to achieving sustainable development. However, they did not quantify future energy (and electricity) demand and emissions. IEA (2016a) and EIA (2018) give an overview of energy

\footnotetext{
$\overline{2}$ Five key energy-intensive industrial subsectors with detailed information on energy savings are included in Sect. 2. Studies on CTI, a light industry, focus more on $\mathrm{CO}_{2}$ emissions and less on energy savings. Therefore, we include electricity-saving opportunities for CTI in the section of Results and discussion (Sect. 4.2.6).
}

efficiency improvement in China's industry but provide limited information on industrial electricity use. ERI (Dai et al., 2013), LBNL (Zhou et al., 2011) and THU (Zhou et al., 2018b) disaggregate China's industrial sector into key energy-intensive subsectors, such as iron \& steel, cement, non-ferrous metals, pulp \& paper and chemical. However, there is little information available on sectoral energy/electricity use and their contributions to electricity savings.

Iron \& steel industry Table 1 indicates 18 studies that focus on energy savings and emission reduction in China's iron \& steel industry (CISI). Most notably, He and Wang (2017) summarized detailed parameters of 158 available energy efficiency technologies (EETs) used in iron \& steel plants around the world. Chen et al. (2014) and Ma et al. (2016) employed the China-TIMES (MARKAL-EFOM System) model to simulate the future energy-saving potentials of 10 and 28 EETs in CISI, respectively. Based on energy conservation supply curves (ECSC), Li and Zhu (2014), Hasanbeigi et al. (2013b), Zhang et al. (2014), Ma et al. (2015a), Zhang (2015a) and Zhang (2017, 2018) identified optimum EET options from an economic perspective. In summary, these studies indicate production structure adjustment (i.e. shift from Basic Oxygen Furnace (BOF) to Electric Arc Furnace (EAF)) and technological progress as the main forces to reduce future energy use and emissions in CISI. In addition, actions to improve energy efficiency by EETs can bring synergies for climate change, air quality and public health to be achieved cost-effectively (Wu et al., 2016).

Cement industry 12 studies focus on energy efficiency improvement and emission mitigation in China's cement industry (CCI, Table 1). Xu et al. (2012) showed that $25 \%$ of energy use (2009) could be saved if best available technologies were implemented. Hasanbeigi et al. (2013a) evaluated the cumulative saving potentials (CSPs) and associated $\mathrm{CO}_{2}$ emission reduction of 23 technologies in the period 2010 to 2030. However, CSPs provide limited transparency for policy-makers for understanding energy savings and emission reductions by year, when designing policies. To fill this gap, Wen et al. (2015a) and Li et al. (2017) simulated the future trends of energy consumption and $\mathrm{CO}_{2}$ emissions using single-objective optimization models. Zhang et al., (2015b, 2015c, 


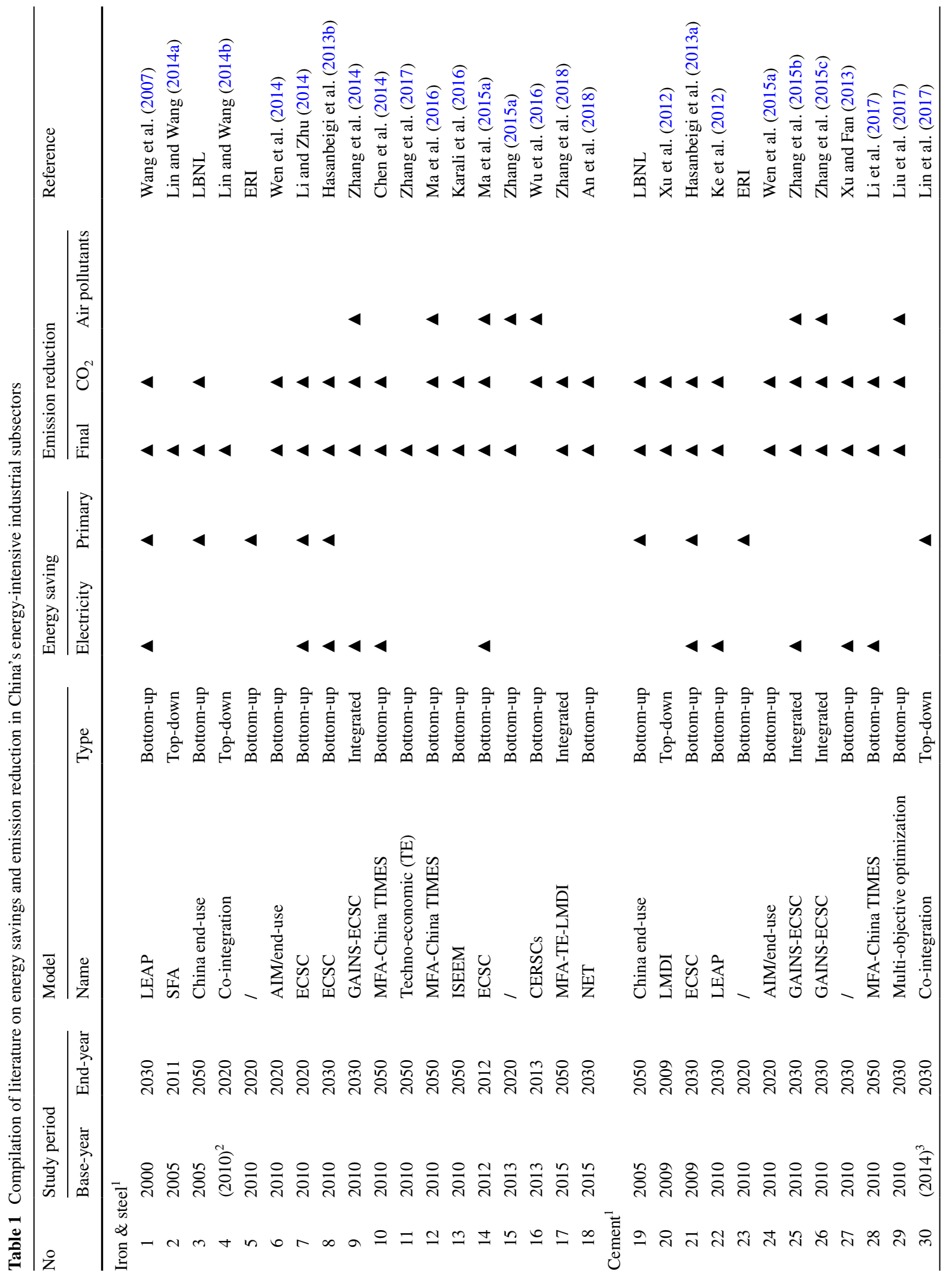




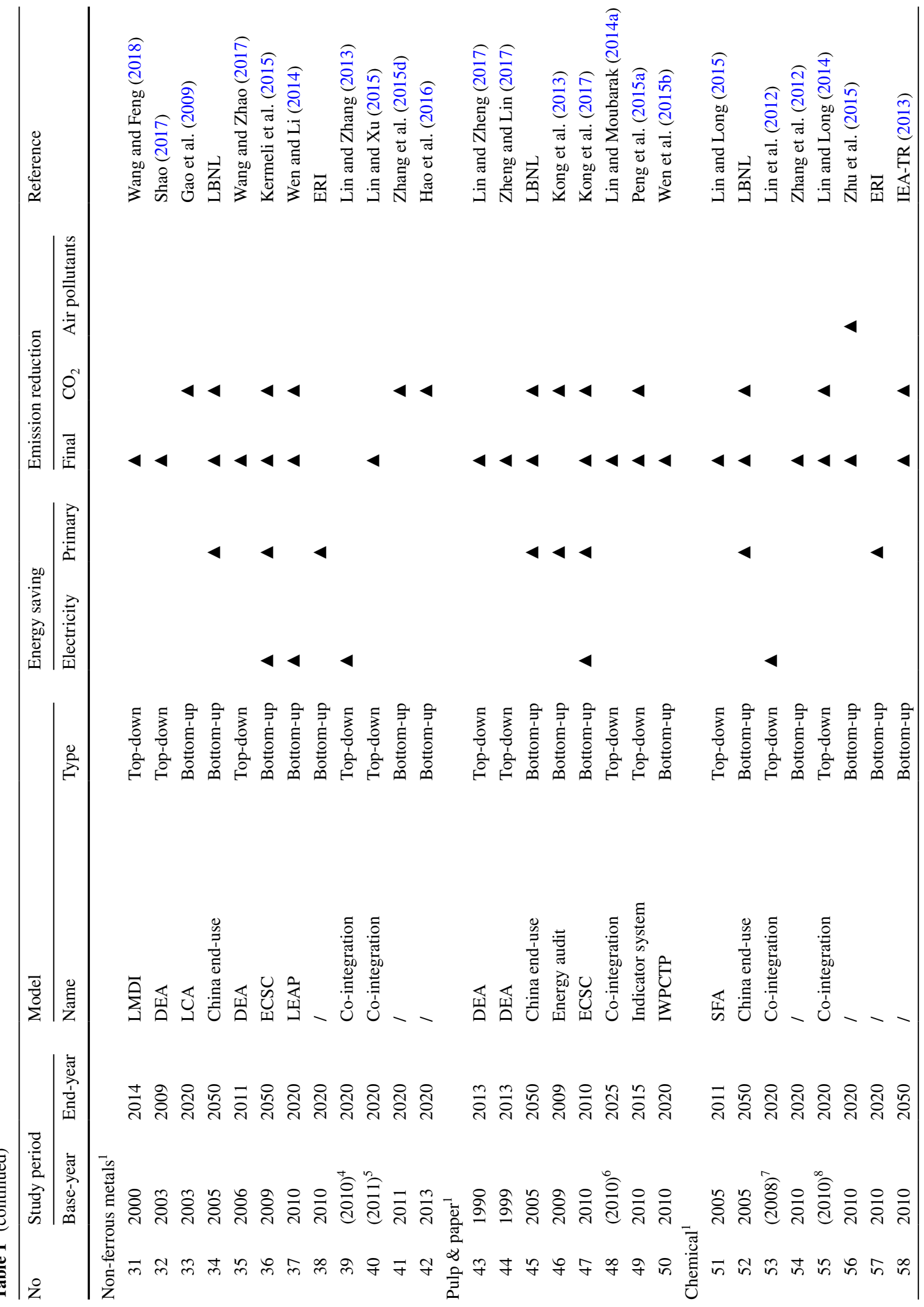




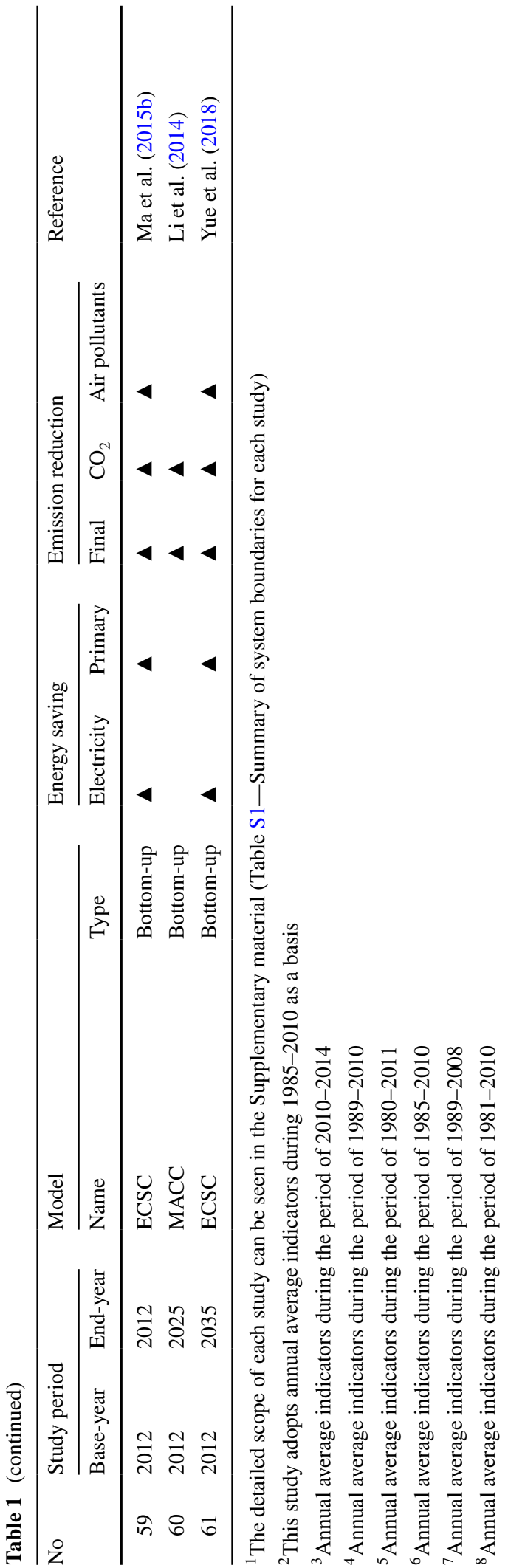

2016) modeled the multiple benefits of 37 EETs in energy savings and emission reduction $\left(\mathrm{CO}_{2}\right.$ and air pollutants) as well as health effects contributed by $\mathrm{PM}_{2.5}$ from CCI for the period 2010-2030 at various regional levels. Yang et al., (2013a, 2013b) estimated the benefits of 18 mitigation measures, monetized in $\$ / t-\mathrm{CO}_{2}$ by MACCs (marginal abatement cost curves), at national and provincial level. In summary, the studies indicate that improving energy efficiency, switching to low-carbon fuels, reducing the clinkerto-cement ratio and integrating carbon capture into cement production are the main energy saving and carbon mitigation measures which support a transition to sustainability in the cement sector. The integration of carbon capture technologies and reducing of the clinker content in cement are identified to provide the largest cumulative $\mathrm{CO}_{2}$ emission reductions in a long-term perspective.

Non-ferrous metals industry Table 1 includes 12 studies that investigate energy efficiency and carbon emission reduction in China's non-ferrous metals industry (CNFMI). Based on a top-down approach, Wang and Feng (2018), Shao (2017) and Wang and Zhao (2017) examined the energy efficiency performance of CNFMI and found that an energy efficiency improvement potential of more than $20 \%$ remains in CNFMI. Because the CNFMI sector consists of multiple products, it is difficult for bottom-up models to cover all production processes. Thus, bottom-up models are used to analyze specific subsectors. For example, Gao et al. (2009), Zhang et al. (2015d) and Hao et al. (2016) predicted the GHG emissions in 2020 for China's primary aluminum industry by assuming different levels of electricity intensity $(\mathrm{kWh} / \mathrm{t}-\mathrm{Al})$ based on national plans. Wen and Li (2014) evaluated the energy-saving potentials of 67 EETs for five main non-ferrous metals (aluminum, copper, lead, zinc and magnesium) during 2010-2020. Kermeli et al. (2015) assessed the technical and economic potentials of 22 EETs for aluminum industry at global level (including China) up to 2050. In summary, both technological progress and rising electricity prices have greatly promoted the decline in energy consumption and GHG emissions. In addition, promoting non-ferrous metals recycling through the implementation of circular economy is also of great importance to reduce energy consumption in the future. As the transition to clean power generation cannot be achieved short-term, 
decision-makers can prioritize the use of EETs to achieve energy saving and emission reduction targets in CNFMI (Wen and Li, 2014; Zhang et al. 2015d).

Pulp \& paper industry As shown in Table 1 and Table S2 (Supplementary material), several approaches have been adopted to analyze energy efficiency and intensity, yet few have evaluated the energy-saving potential in China's pulp \& paper industry (CPPI). Lin and Zheng (2017) and Zheng and Lin (2017) studied energy efficiency using a total factor energy index, implying that CPPI could save at least $40 \%$ of its energy use. Kong et al. (2017) estimated the energy-saving potentials of 23 available EETs in 2010. Research on future energy savings at the national level is limited (Lin \& Moubarak, 2014a; Wen et al., 2015b; Zhou et al., 2011). Lin and Moubarak (2014a) established relationships between economic variables to forecast the energysaving potentials up to 2025. Wen et al. (2015b) evaluated the co-benefits of 14 EETs on energy savings and water-pollution reduction from 2010 to 2020 by industrial water pollutant control and technology policy (IWPCTP) model. These studies indicate that efforts to improve energy efficiency will benefit both the economy and the environment by reducing energy costs and emissions of water pollutants and GHG. Closing small capacity and updating production technology have been identified as effective ways to improve energy efficiency in the CPPI. China's NDRC (2018) and MIIT (2012) also pointed out that dry-wet stock preparation, high-efficiency pulp washing and efficient double-disc refiner are efficient technologies that both conserve energy and mitigate emissions. In addition, 36 emerging technologies to substantially reduce energy use and GHG emissions compiled by Kong et al. (2012) should be promoted.

Chemical industry Research on China's chemical industry (CCMI) is mainly limited to energy efficiency evaluation (Han et al., 2015; Lin and Long, 2014, 2015; Lin et al., 2012) and carbon emissions (Kahrl et al., 2010; Lin and Long, 2016; Liu et al., 2011; Zhou et al., 2010; Zhu et al., 2010). Only a few studies focus on future efficiency improvement potentials in CCMI and its subsectors, especially for electricity demand (Table 1). The chemical industry is a multi-product sector. Top-down approaches (Lin \& Long, 2014, 2015; Lin et al., 2012) used aggregated economic indicators to describe the industry as a whole. Lin and Long (2015) explored the performance of energy efficiency in CCMI during 2005-2011 and showed that energy efficiency could be further improved by $31 \%$. IEA (2013) identified that radical improvement of energy efficiency in the global chemical industry can save 5.3 EJ by 2050. Ma et al. (2015b) estimated fuel and electricity savings for 26 EETs, applicable to China's ammonia industry in 2012. Li et al. (2014) studied the energy efficiency improvement for the chlor-alkali industry in Shandong Province. Technological progress has proven an efficient way to improve energy efficiency. Studies on how to achieve the potentials by specific technologies are rare. Zhu et al. (2015) and Zhang et al. (2012) identified technological opportunities for energy savings and water-pollution reduction for ammonia production in the short term. Yue et al. (2018) estimated the electricity-saving potentials and associated emission reduction (GHG and air pollutants) of 60 electricity-saving measures in CCMI, covering 4 electricity-intensive chemicals. These studies reveal that efficient technology promotion and switching feedstocks (ammonia: coal-based to natural gas-based; PVC: calcium carbide-based to ethylene-based) are the main factors to reduce energy use and emissions of water and air pollutants. Increasing energy prices can drive the diffusion of EETs.

\section{Modeling factor identification}

Model-based scenario analysis nowadays plays a key role in informing decision-makers about future trends in the energy system. However, a slightly different hypothesis or scenario storyline can result in large differences in projected energy consumption. Therefore, it is necessary to understand studies in terms of their system boundaries, data sources, modeling approaches, key driver assumptions, assumed policy instruments and explicit technologies modeled.

Firstly, as shown in Table S2, the base-year final energy and electricity use varies in the included studies as a result of different input data and system boundaries. For example, China's iron and steel sector as identified in Zhang et al. (2014) shows a lower final energy use in base-year 2010, of $16 \mathrm{EJ}$, compared to Hasanbeigi et al. (2013b) (from China's Statistics Bureau-CSB (NBS 2017)) and ERI (Dai 
et al., 2013), which is around 17 EJ. The processes of steel production and its specific energy consumption differ between various studies (Chen et al., 2014; Karali et al., 2016; Ma et al., 2016; Wen et al., 2014), and conflict with statistics for 2010 (ERI and CSB). The studies (Li and Zhu, 2014; Zhang et al., 2017) are based on the same energy consumption per unit product $(17.72 \mathrm{GJ} / \mathrm{t}$-steel) to explore future energy efficiency improvement. Different statistical methods and system boundaries (e.g. the major process energy intensity of iron \& steel in the GAINS model is lower than official data in 2010) are responsible for the divergences of base-year energy consumption among the listed studies (Zhang et al., 2014).

Secondly, modeling approaches and included drivers are key factors that affect projections. Various modeling approaches are used to analyze energy-saving potentials (Table 1). These can be classified into three general types: (1) top-down models, (2) bottomup models and (3) integrated models (Karali et al., 2012). The drivers used typically vary per modeling approach (Table S3 for an overview of the key drivers used in the included studies). Top-down models (e.g. SFA, co-integration and LMDI) have a macroeconomic perspective and use socio-economic variables to predict energy use developments. Sectoral economic activities are represented through aggregated production functions. For example, the studies (Lin and Zhang, 2013; Lin et al., 2012) evaluated the electricity-saving potentials in CNFMI and CCMI by 2020 based on top-down approaches. However, topdown approaches (characterized by implicit technology representation like $R \& D$ progress) fail to capture technological details of energy conservation and are unable to incorporate different assumptions about how discrete EETs and costs will evolve in the future (Table S4) (Karali et al., 2012). In the list of Table 1, bottom-up models with specific technology representation are widely used to explore future energy demand and emissions in different sectors. However, some studies using bottom-up models (e.g. ECSC, ISEEM, NET and IWPCTP) include very limited interactions with the macro-economic system (Table S3). Integrated models (e.g. GAINS-ECSC and MFA-TE-LMDI) combine top-down and bottomup modeling approaches through hard or soft linking. However, integrated models are typically limited in the amount and details of key drivers compared to top-down or bottom-up models alone (Table S3).
Detailed strengths and weaknesses of various models used in China were assessed by Zhang et al. (2015d) and Mischke et al. (2014). Additionally, power pinch method based on the concept of thermodynamics is widely used to analyze energy efficiency gap (Klemeš et al., 2018), but the applied coverages are mostly on optimizing hybrid power systems from the supply side (Rozali et al., 2014, 2019), rarely on quantitatively estimating the electricity savings in the demand side (Hackl \& Harvey, 2013) for China, like industry and building. Therefore, the power pinch analysisrelated studies are out of this research scope focusing on industrial efficiency improvements in terms of electricity. While the pinch method should be given more attention to extend the application in annual strategic deployment of energy conservation, or to explore more efficient energy systems in combination with the demand side.

Thirdly, although some studies use the same model, the policy instruments or type and specific EETs modeled in alternative scenarios can result in different results for energy savings. Tables S4 and S5 give an overview of policy instruments and specific technologies modeled in the different studies, respectively. Technology selection and diffusion are the main factors that affect energy savings in the studies using bottom-up approaches. For example, study (Li and Zhu, 2014) collected 41 EETs for CISI, while 25 technologies are cost-effective. The results show that the technical and cost-effective energy savings are $4.63 \mathrm{GJ} / \mathrm{t}$ and $3.89 \mathrm{GJ} / \mathrm{t}$, respectively, which are higher than the results from study (Zhang et al., 2017) (also on the basis of an ECSC model), i.e. $3.08 \mathrm{GJ} / \mathrm{t}$ and $1.93 \mathrm{GJ} / \mathrm{t}$. The main reasons are the inclusion of more EETs for EAF-steelmaking, casting, rolling and finishing processes in study ( $\mathrm{Li}$ and Zhu, 2014) than study (Zhang et al., 2017) (Table S5).

\section{Results and discussion}

Based on the literature collection in Table 1, a comparative analysis of electricity savings for China's five key industrial subsectors is conducted. Moreover, the share of electricity savings in total final energy savings is assessed for each sector to understand the role electricity savings can play in reducing industrial energy use and providing an intuitive understanding of the relationship between electricity savings and 
Table 2 Energy-saving potentials in different sectors (relative to baseline levels)

\begin{tabular}{|c|c|c|c|c|c|c|c|c|}
\hline \multirow[t]{2}{*}{ Sector } & \multicolumn{2}{|l|}{2020} & \multicolumn{2}{|l|}{2030} & \multicolumn{2}{|l|}{2040} & \multicolumn{2}{|l|}{2050} \\
\hline & $\begin{array}{l}\text { Final energy } \\
(\%)\end{array}$ & $\begin{array}{l}\text { Electricity } \\
(\%)\end{array}$ & $\begin{array}{l}\text { Final energy } \\
(\%)\end{array}$ & $\begin{array}{l}\text { Electricity } \\
(\%)\end{array}$ & $\begin{array}{l}\text { Final energy } \\
(\%)\end{array}$ & $\begin{array}{l}\text { Electricity } \\
(\%)\end{array}$ & $\begin{array}{l}\text { Final energy } \\
(\%)\end{array}$ & $\begin{array}{l}\text { Electricity } \\
(\%)\end{array}$ \\
\hline Industry & $4(2-8)$ & $4(2-5)$ & $11(7-17)$ & $10(6-15)$ & $17(6-28)$ & $14(7-24)$ & $21^{*}$ & $3^{*}$ \\
\hline \multicolumn{9}{|l|}{ Subsectors } \\
\hline $\begin{array}{c}\text { Iron \& } \\
\text { steel }\end{array}$ & $10(1-51)$ & $16(13-17)$ & $11(2-31)$ & $23(13-31)$ & $12(5-20)$ & / & $16(5-32)$ & I \\
\hline Cement & $10(5-20)$ & $8(4-21)$ & $18(2-34)$ & $15(10-33)$ & $18(15-21)$ & $19^{*}$ & $27(19-38)$ & $15(9-18)^{*}$ \\
\hline $\begin{array}{l}\text { Non- } \\
\text { ferrous } \\
\text { metals }\end{array}$ & $22(1-59)$ & $25(6-52)$ & $2^{*}$ & I & $6^{*}$ & I & $10^{*}$ & I \\
\hline $\begin{array}{l}\text { Pulp \& } \\
\text { paper }^{* *}\end{array}$ & $24(1-39)$ & / & $1^{*}$ & / & $2^{*}$ & I & $2^{*}$ & / \\
\hline Chemical & $12(6-27)$ & $24(8-50)$ & $29^{*}$ & $25(22-28)^{*}$ & $25^{*}$ & I & $22^{*}$ & I \\
\hline
\end{tabular}

* Based on only one study

** Based on one study, CPPI can save $4 \%$ of electricity use in 2010 , but future electricity savings are unavailable

Table 3 Energy-saving contributions at sector level (absolute savings)

\begin{tabular}{|c|c|c|c|c|c|c|c|c|}
\hline \multirow[t]{2}{*}{ Sector } & \multicolumn{2}{|l|}{2020} & \multicolumn{2}{|l|}{2030} & \multicolumn{2}{|l|}{2040} & \multicolumn{2}{|l|}{2050} \\
\hline & $\begin{array}{l}\text { Final energy } \\
(\mathrm{EJ})\end{array}$ & $\begin{array}{l}\text { Electricity } \\
\text { (TWh) }\end{array}$ & $\begin{array}{l}\text { Final energy } \\
(\mathrm{EJ})\end{array}$ & $\begin{array}{l}\text { Electricity } \\
\text { (TWh) }\end{array}$ & $\begin{array}{l}\text { Final energy } \\
(\mathrm{EJ})\end{array}$ & $\begin{array}{l}\text { Electricity } \\
\text { (TWh) }\end{array}$ & $\begin{array}{l}\text { Final energy } \\
(\mathrm{EJ})\end{array}$ & $\begin{array}{l}\text { Electricity } \\
\text { (TWh) }\end{array}$ \\
\hline Industry & $\begin{array}{l}3.00(0.80- \\
6.80)\end{array}$ & $137(69-190)$ & $\begin{array}{c}7.60(3.90- \\
13.90)\end{array}$ & $\begin{array}{l}435(280- \\
721)\end{array}$ & $\begin{array}{l}11.50(5.50- \\
20.90)\end{array}$ & $\begin{array}{c}770(240- \\
1396)\end{array}$ & $12.60^{*}$ & $110^{*}$ \\
\hline \multicolumn{9}{|l|}{ Subsectors } \\
\hline $\begin{array}{r}\text { Iron \& } \\
\text { steel }\end{array}$ & $\begin{array}{c}2.13(0.11- \\
16.98)\end{array}$ & $93(49-121)$ & $\begin{array}{l}1.65(0.21- \\
6.26)\end{array}$ & $149(37-212)$ & $\begin{array}{l}1.07(0.42- \\
2.16)\end{array}$ & l & $\begin{array}{l}1.19(0.41- \\
2.57)\end{array}$ & I \\
\hline Cement & $\begin{array}{c}0.64(0.25- \\
1.30)\end{array}$ & $15(8-37)$ & $\begin{array}{l}1.03(0.12- \\
3.36)\end{array}$ & $23(16-44)$ & $\begin{array}{l}1.00(0.46- \\
1.38)\end{array}$ & $24^{*}$ & $\begin{array}{c}1.19(0.55- \\
1.82)\end{array}$ & $14(8-17)$ * \\
\hline $\begin{array}{l}\text { Non- } \\
\text { ferrous } \\
\text { metals }\end{array}$ & $\begin{array}{l}0.55(0.01- \\
1.46)\end{array}$ & $80(22-164)$ & $0.03^{*}$ & I & $0.11^{*}$ & I & $0.22^{*}$ & l \\
\hline $\begin{array}{l}\text { Pulp \& } \\
\text { paper }\end{array}$ & $\begin{array}{l}0.31(0.01- \\
0.51)\end{array}$ & l & $0.02^{*}$ & I & $0.02^{*}$ & l & $0.03^{*}$ & l \\
\hline Chemical & $\begin{array}{l}0.90(0.17- \\
2.95)\end{array}$ & $69(23-141)$ & $0.75^{*}$ & $100(89-111)$ & $0.60^{*}$ & I & $0.47^{*}$ & l \\
\hline Subtotal & $0.55-23.20$ & & $1.13-10.42$ & & $1.61-4.27$ & & $1.68-5.11$ & \\
\hline
\end{tabular}

*Based on only one study

** Future electricity savings are unavailable for CPPI

total energy savings. Opportunities to improve electricity efficiency in China's textile sector are also discussed. A detailed description of final energy consumption is presented in the Supplementary material. Finally, the synergies of electricity saving in relation to climate change and air quality are quantified (Tables 2, 3 and 4).
China's industry

Figure 3 shows the future electricity consumption and saving potentials in China's industry. Industrial electricity consumption grows steadily in all IEA scenarios (IEA, 2016a), with an average annual rate of $1.8 \%$ (with a range of $1.2-2.3 \%$ ), which is higher 
Table 4 Co-benefits of electricity savings in terms of emission reduction in China's industry

\begin{tabular}{lcccl}
\hline Emission & 2020 & 2030 & 2040 & 2050 \\
\hline GHGs & & & & \\
$\mathrm{CO}_{2}(\mathrm{Mt})$ & $55-152$ & $224-577$ & $192-1118$ & 88 \\
$\mathrm{CH}_{4}(\mathrm{t})$ & $574-1579$ & $2327-5993$ & $1995-11,603$ & 914 \\
$\mathrm{~N}_{2} \mathrm{O}(\mathrm{t})$ & $820-2257$ & $3326-8565$ & $2851-16,584$ & 1307 \\
Air pollutants & & & & \\
$\mathrm{SO}_{2}(\mathrm{kt})$ & $111-305$ & $449-1157$ & $385-2241$ & 177 \\
$\mathrm{NO}_{\mathrm{x}}(\mathrm{kt})$ & $117-321$ & $474-1220$ & $406-2362$ & 186 \\
$\mathrm{PM}_{2.5}(\mathrm{kt})$ & $26-73$ & $107-276$ & $92-534$ & 42 \\
\hline
\end{tabular}

Calculated by authors (see Supplementary material) future due to accelerated end-use electrification. As shown in Fig. 4, the share of electricity consumption in industrial final energy use is expected to increase from an average of $24 \%$ in 2015 (range 20-28\%) to $33 \%$ in 2040 (range 21-39\%). Meanwhile, electricity savings are estimated to be $31 \%$ (with a range of $23-39 \%), 26 \%(20-29 \%)$ and $25 \%(11-33 \%)$ of total industrial final energy saving in 2020, 2030 and 2040, respectively. Promoting electricity conservation therefore is an effective way to reduce overall consumption in China's industry.

China's industrial subsectors

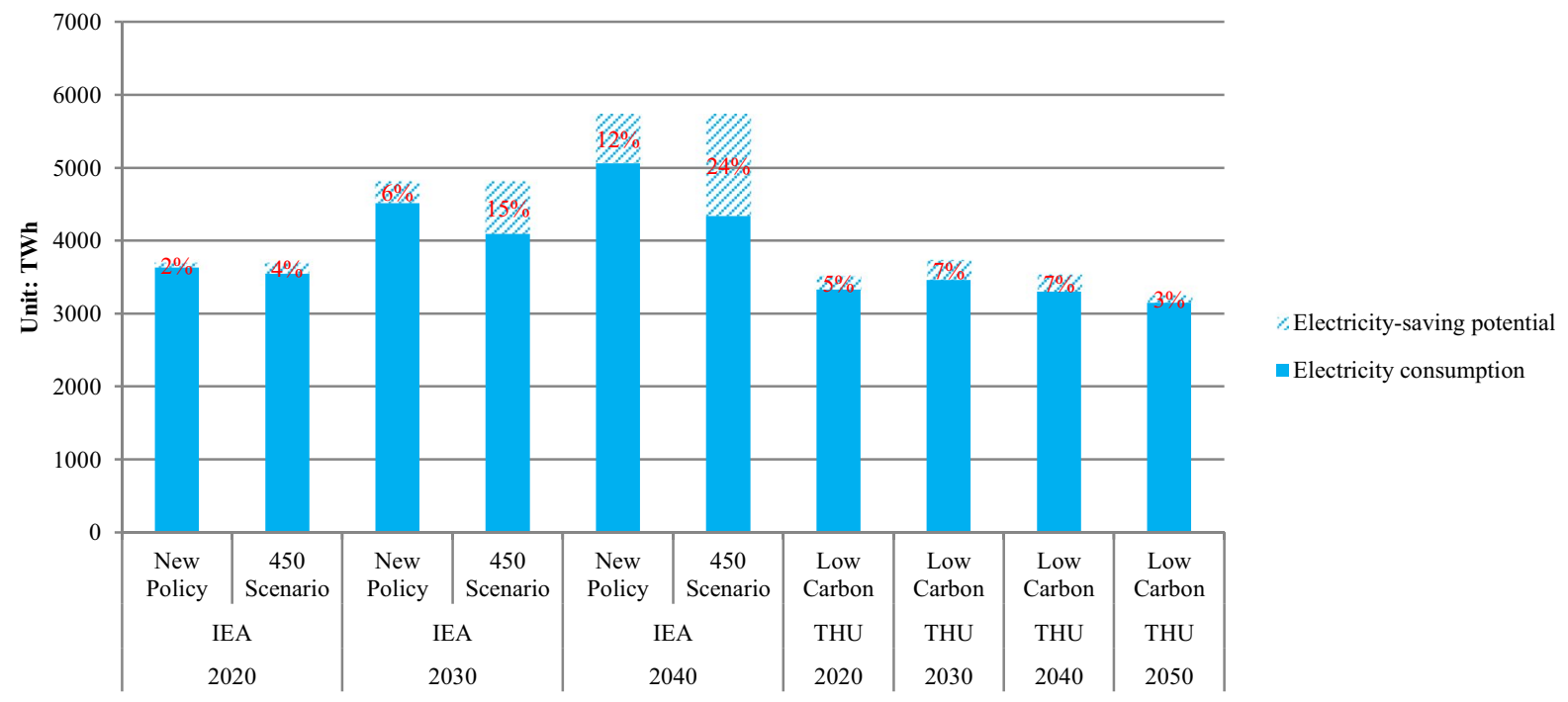

Fig. 3 Electricity consumption and saving potentials in China's industry

than the annual growth rate of industrial final energy use of $0.5 \%(-0.2-1.1 \%)$. The projected electricity use in 2020 for IEA's 450 and THU's Reference scenarios (Zhou et al., 2018b) are similar. THU predicts that electricity use will peak at 2025, with an average annual growth rate of $0.8 \%$ during 2015-2025 (range $0.5-1.2 \%$ ), and then decline with $0.5 \%$ after 2025 (range $0.5-0.6 \%$ ). In comparison to the baseline scenarios, industrial electricity consumption is expected to decrease by $4 \%$ in 2020 (range 2-5\%), $10 \%$ in 2030 (range 6-15\%), 14\% in 2040 (range 7-24\%) and 3\% in 2050 .

China's industrial energy system is expected to shift to higher electricity and lower fossil fuels in the
Iron \& steel industry

As shown in Table 1, six studies focus on the electricity-saving potentials in CISI. Some of these studies (Hasanbeigi et al., 2013b; $\mathrm{Li}$ and $\mathrm{Zhu}, 2014$; Ma et al., 2015a) show that with proven EETs a considerable amount of electricity can be avoided. Only two studies (Wang et al., 2007; Zhang et al., 2014) present the evolution of electricity use and efficiency improvements in the future (Fig. 5). Electricity use in CISI is expected to peak around 2020 and then decline slightly (by $0.1-0.4 \%$ per year) till to 2030. With the diffusion of advanced technologies, 
Fig. 4 Share of electricity in China's industrial final energy use

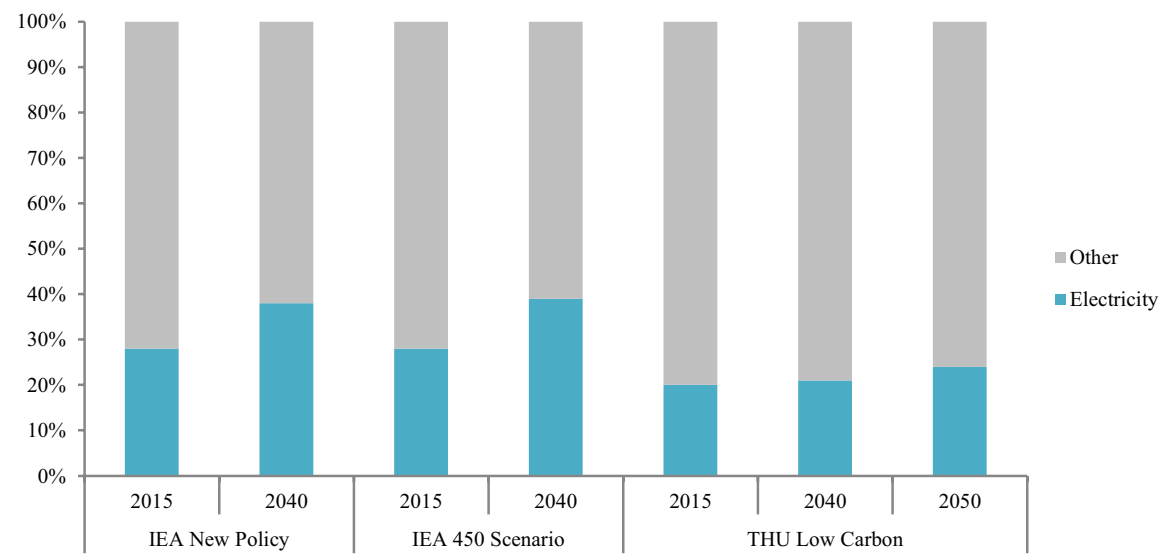

Fig. 5 Electricity-saving potentials in CISI compared to the baseline

electricity intensity would be able to decrease, with $10 \%$ in 2020 (range $8-12 \%$ ) and $23 \%$ in 2030 (range $18-27 \%)$. The electricity-saving potential is estimated to be $16 \%$ in 2020 (range 13-17\%) and $23 \%$ in 2030 (range 13-31\%), compared to the baseline.

Driven by the increasing proportion of EAF, electricity consumption is expected to increase from $10 \%$ of final energy use of CISI in 2010 to $13-14 \%$ in 2020 and $14-16 \%$ in 2030 . There are not many long-term studies, but Chen et al. (2014) project in a baseline scenario, a share of $22 \%$ in 2050 . Generally, the proportion of coal keeps declining in the final energy mix of CISI, and electricity will increasingly become a more dominant energy carrier. Efficient use of electricity can save $2-3 \%$ and $2-5 \%$ of final energy use of CISI in 2020 and 2030, which accounts for $11-12 \%$ and $10-12 \%$ of energy savings in 2020 and 2030, respectively. Five major processes (coke 


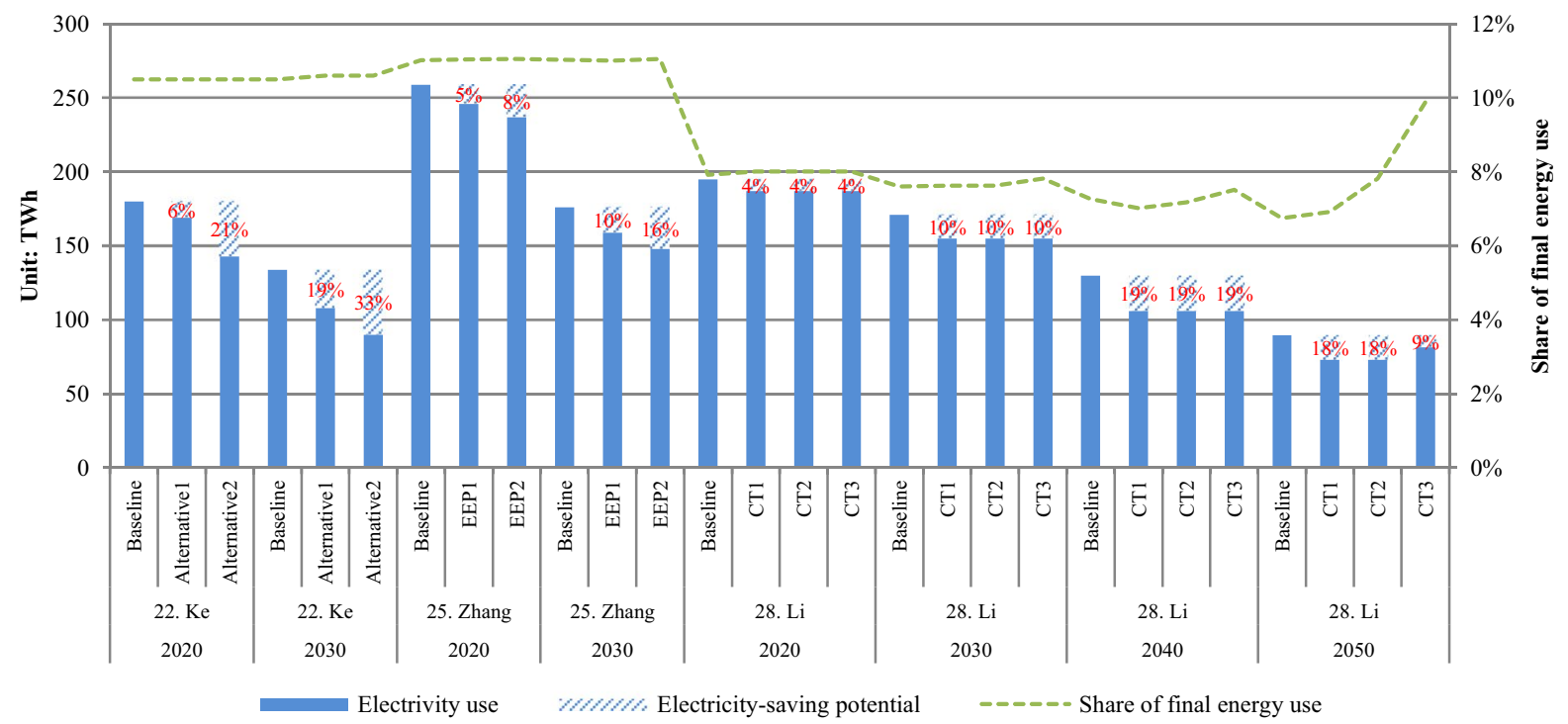

Fig. 6 Electricity-saving potentials in CCI compared to the baseline

making, sintering, iron making, steel making, and casting, rolling \& finishing) are involved in steel production (see Table S1). The largest potential of electricity savings is found in the process of casting, rolling and finishing, which contributes to around 52\% of the electricity savings in the steel industry. Direct rolling technology is one of the key cost-effective measures to reduce electricity demand in the finishing mills. Besides improving the casting and rolling process, considerable potentials of electricity savings are expected by promoting the penetration of new EAF systems such as direct current arc furnaces and twin shell furnaces.

\section{Cement industry}

Figure 6 and Table 2 show the electricity-saving potential in China's cement sector. The included studies mainly focus on the short term (i.e. 2010-2030). Baseline scenarios show that electricity use in CCI will approach a peak of $211 \mathrm{TWh}$ in 2020 (range 180-259 TWh) and then decline to $90 \mathrm{TWh}$ by 2050 . Compared to the baseline, electricity use can be reduced by $8 \%$ in 2020 (range $4-21 \%$ ), $15 \%$ in 2030 (range 10-33\%) and $15 \%$ in 2050 (range 9-18\%). Compared to 2010, the electricity intensity is expected to be able to decrease by $27 \%$ in 2030 (range of $20-33 \%$ ) and thereafter reach world best practice level (i.e. 54-60 kWh/t-cement) in 2050 (Worrell et al., 2008).

Electricity accounts for around $10 \%$ (range $8-11 \%$ ) of final energy use and changes not significantly during the period 2010 to 2030. Around $10 \%$ (range $6-16 \%$ ) and $10 \%$ (range $6-14 \%$ ) of final energy savings are contributed to electricity savings in 2020 and 2030, respectively, which account for $1 \%$ and $2 \%$ of final energy use. There are not many long-term studies, but $\mathrm{Li}$ et al. (2017) project that the share of electricity use would grow if a carbon tax increased from $50 \$ / \mathrm{t}-\mathrm{CO}_{2}$ in 2020 to $215 \$ / \mathrm{t}$ $\mathrm{CO}_{2}$ in 2050. The main reason is that the tax will promote energy system changes towards lower coal and higher electricity. Around $1.5 \%$ of final energy use can be saved by improving electricity efficiency in 2050. Cement manufacturing consists of four major production processes, i.e. fuel preparation, raw material preparation, clinker making, grinding and finishing. Around 50\% of the electricitysaving potential can be released through improving the electricity use efficiency in the processes of raw material preparation and cement grinding. It is worth noting that general measures, such as highefficiency motors and energy management systems, have huge potentials to reduce electricity demand. These measures represent around $20 \%$ of total electricity savings in the cement sector. Meanwhile, 


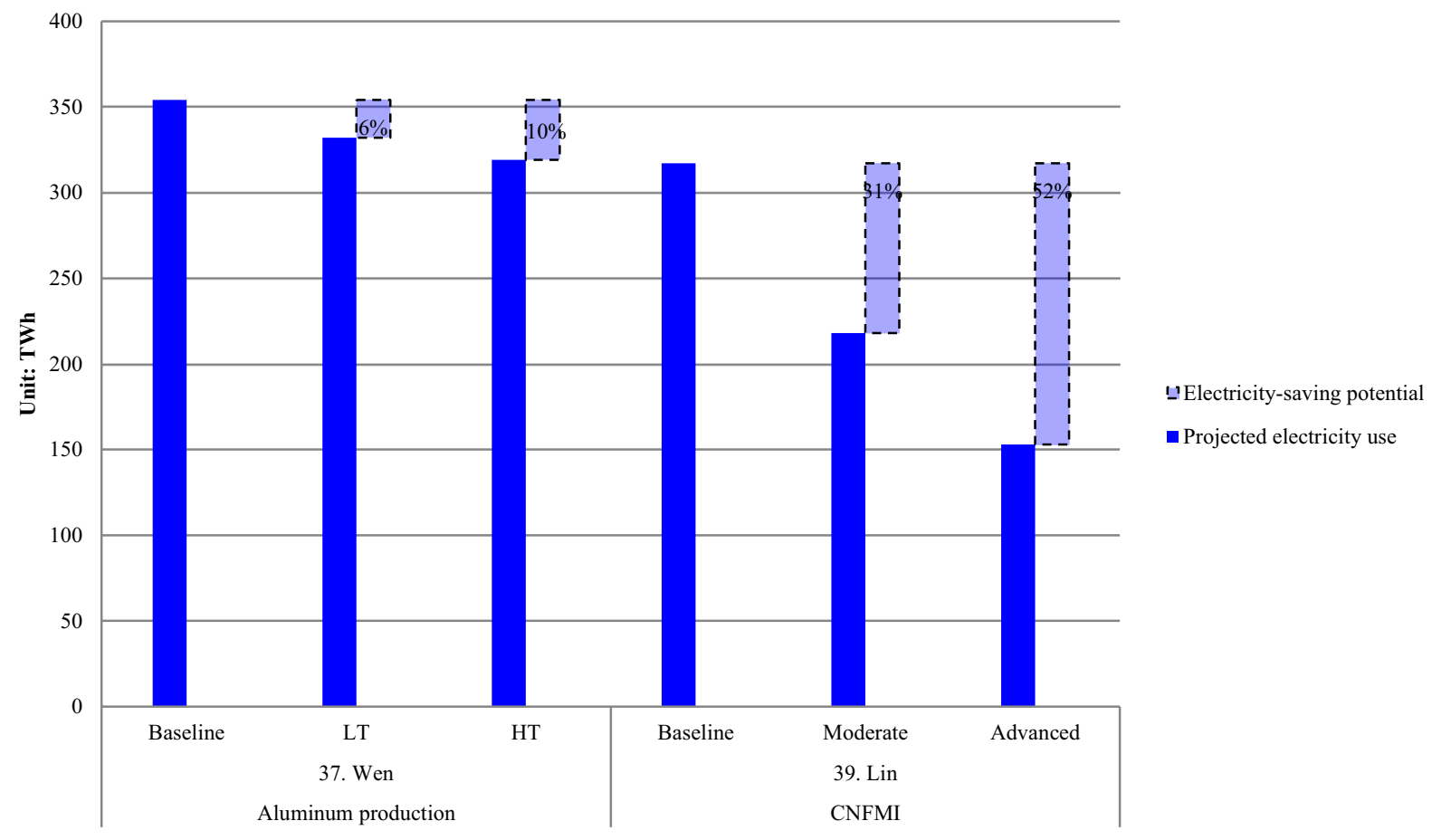

Fig. 7 Electricity-saving potentials in China's non-ferrous metals sector in 2020

most of the general measures are economically feasible for investors.

\section{Non-ferrous metals industry}

Research for the CNFMI is mainly concentrated on two aspects, i.e. GHG emissions (Gao et al., 2009; Zhang et al. 2015d; Hao et al., 2016) and historical energy efficiency investigations (Shao, 2017; Wang and Feng, 2018; Wang and Zhao, 2017). Studies on predicting the energy conservation trajectory in the whole non-ferrous metals industry are rare. As shown in Table 1, most of these studies focus on aluminum production because it accounts for $74 \%$ and $75 \%$ of total energy consumption and electricity consumption in the whole non-ferrous metals industry, respectively (CNMIA, 2017).

Future electricity demand in CNFMI will keep growing with the expected increasing demand for nonferrous metals. The increasing electricity demand would result in large indirect emissions of GHG and air pollutants. Figure 7 shows that future electricity savings in the non-ferrous metals sector are considerable in 2020. For the overall non-ferrous metal industry, projected electricity use could be reduced by $41 \%$ in 2020 (with a range of 31-52\%), corresponding to around $132 \mathrm{TWh}$ (range 99-164 TWh). For aluminum production, electricity use is expected to be reduced by $8 \%$ in 2020 (range 6-10\%). Both technological progress and increasing use of secondary metals greatly promote the decline in electricity consumption and GHG emissions. However, increases in the share of secondary production of non-ferrous metals are limited by the availability of scrap (IEA, 2017). Thus, the adoption of cost-effective technologies should be prioritized to improve electricity efficiency and reduce emissions by CNFMI.

As the dominant energy carrier, the share of electricity in final energy use of CNFMI increased from $38 \%$ in 2000 to $66 \%$ in 2016 (NBS 2017). The increased electricity use comes mainly from aluminum production. Electricity consumed by aluminum production accounts for $49 \%$ of total final energy use of CNFMI. In 2020, around 4\% (range $3-5 \%$ ) of final energy use in CNFMI can be avoided by improving electricity efficiency in aluminum production. Electricity savings in aluminum production can contribute to $58 \%$ (range 56-60\%) of energy 
Fig. 8 Electricity-saving potentials for CPPI in 2010

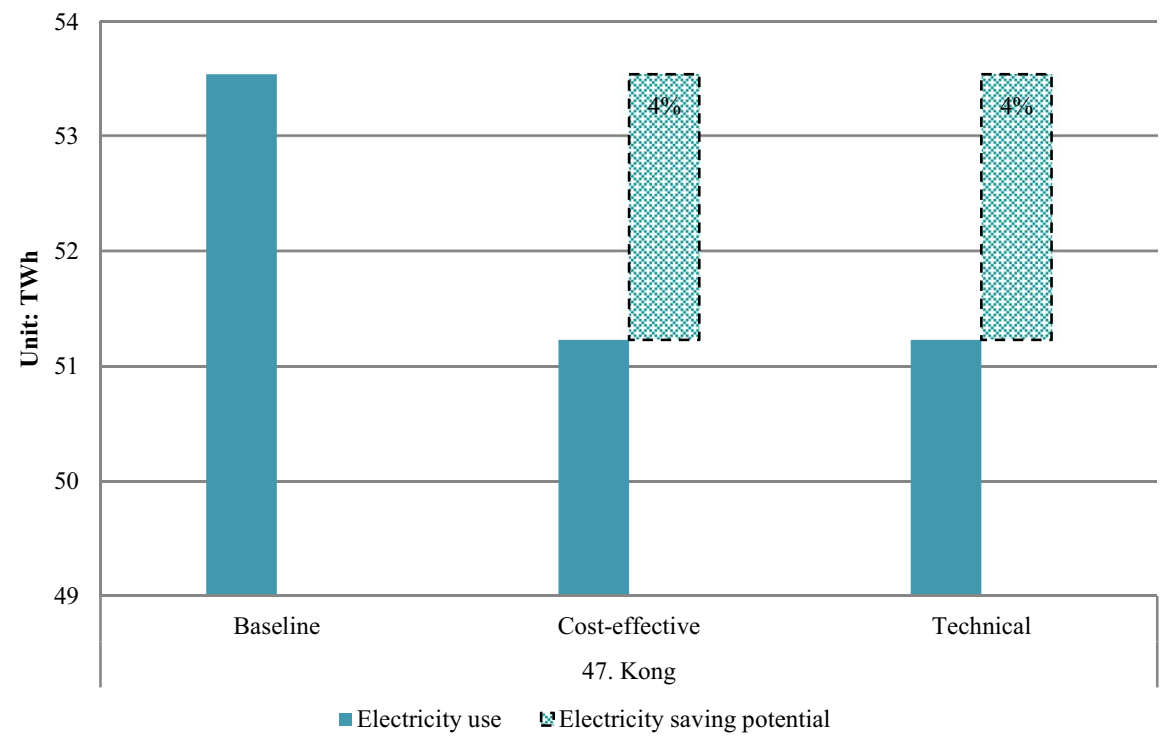

savings of CNFMI in 2020. Saving electricity in aluminum production thus can significantly reduce overall energy consumption in CNFMI. Actions to improve the alumina refining process are expected to unleash around $10 \%$ of total electricity-saving potentials in China's aluminum sector. The most cost-effective way to reduce the electricity intensity of primary aluminum is to retrofit and upgrade outdated electrolytic cells, which can contribute more than $80 \%$ of the total electricity savings in the aluminum sector. Therefore, the government should prioritize the penetration of high-efficiency electrolyzers, such as new reduction cells with low temperature and low voltage, and TiB2/C composite cathodes with high wettability and impermeability.

\section{Pulp \& paper industry}

Figure 8 shows the electricity-saving potentials in CPPI in 2010. Four percent of the electricity use in CPPI can be avoided though implementing 3 process electricity-saving technologies (i.e. vacuum system optimization, high-efficiency double-disc refiners, refiner improvements) and 2 general measures (i.e. adjustable-speed drivers and energy-efficient lighting). It is worth noting that Germany as one of the most efficient paper producers still has $16 \%$ electricity-saving potentials though promoting 11 electricity-saving technologies (Fleiter et al., 2012). As the world's largest paper producer, the electricity savings
(4\%) in China's paper sector thus may be underestimated due to the few technologies included in the study (Kong et al., 2017). The shortcoming makes it difficult for policy-makers to fully understand the electricity savings and emission reduction potentials, and to make reasonable and cost-effective choices.

Similar to other sectors, the energy system of CPPI is shifting towards higher electricity and lower coal use. Final energy consumption has peaked in 2009 and then declined with an average annual rate of $2 \%$ during 2009-2016 (Supplementary material). However, electricity use continued to grow, with an average annual rate of 5\% in the period 2009 to 2016 . The share of electricity demand thereby increased from $18 \%$ in 2000 to $29 \%$ in 2016 . According to Kong et al. (2017), electricity savings (2 TWh) of CPPI can contribute to $3-4 \%$ of energy savings, representing around $1 \%$ of final energy use in 2010 by this sector. However, due to the limited studies and especially scope of included electricity conservation measures, these results are expected to be an underestimation. Two major production processes (i.e. pulping and papermaking) are included in paper manufacturing. Electricity savings in the pulping process account for around $20 \%$ of total electricity savings in CPPI. The papermaking process has the highest potential for reducing electricity use (accounting for nearly $60 \%$ of total electricity savings). Besides these two major processes, approximately $20 \%$ of the electricity-saving potentials can be accessed by cross-cutting 


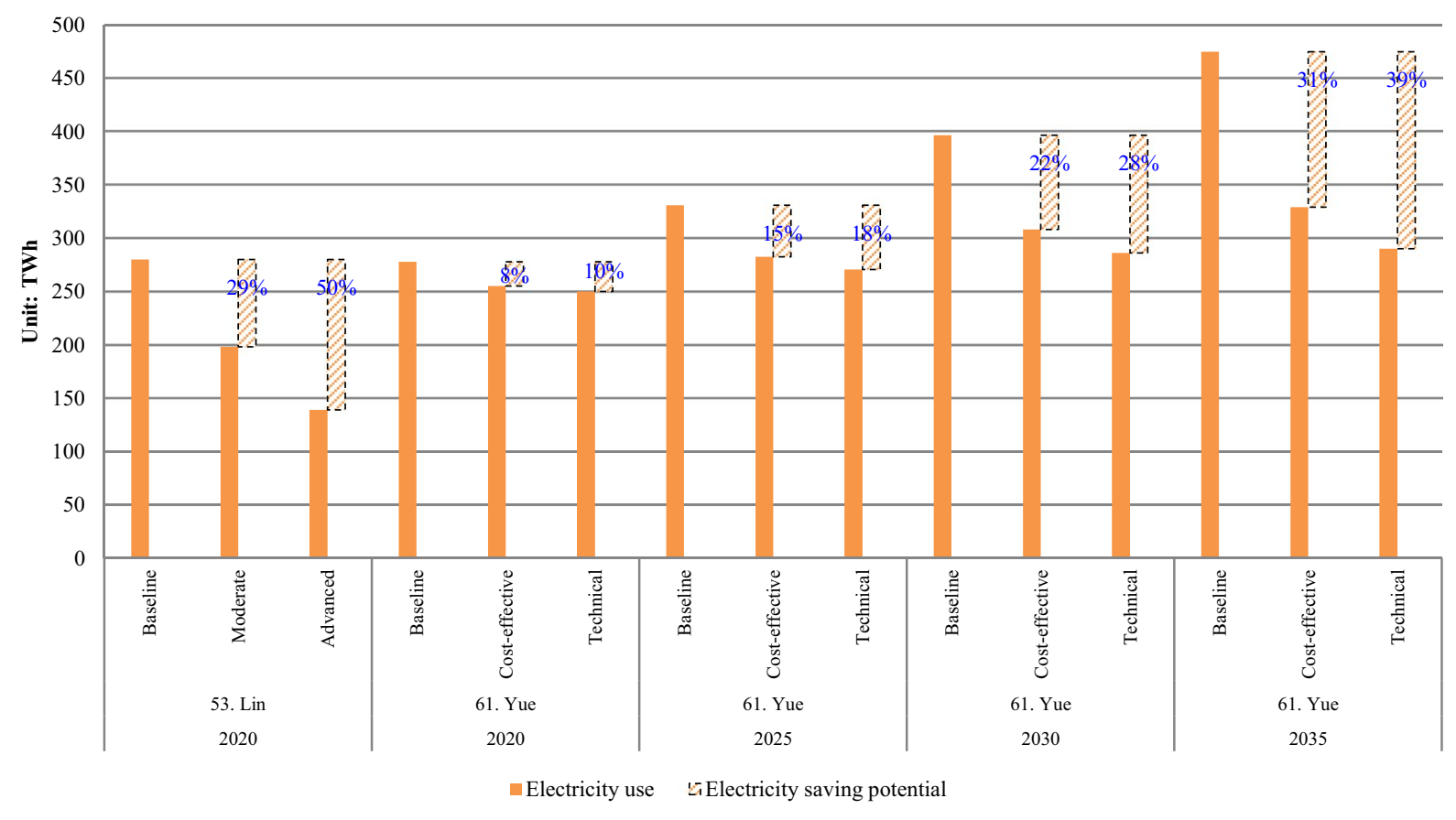

Fig. 9 Electricity-saving potentials in CCMI compared to the baseline. Note: the study 53. Lin studied the electricity use in the whole chemical industry; the study 61. Yue projected the

measures (e.g. adjustable-speed drives and antiscaling technology for cooling water systems). With the increasing share of wood-based pulping (10\% in 2010 to $13 \%$ in 2017 (CTAPI, 2018)), more advanced electricity-saving technologies can be introduced to CPPI, like high-efficiency grinding, enzymatic pretreatment and chemical modification of fibers (Fleiter et al., 2012). It is necessary to build a cost-effective technology roadmap to facilitate the electricity-saving potentials and investments for CPPI in the future.

\section{Chemical industry}

As shown in Fig. 9, only two studies (Lin et al., 2012; Yue et al., 2018) focus on future electricity-saving potentials in the CCMI. Top-down approaches (Lin et al., 2012) show a large electricity saving potential for the overall chemical industry in 2020, of around $40 \%$ (ranging from 29 to 50\%). Bottom-up approaches (Yue et al., 2018), on the other hand, estimate a lower possible reduction of electricity use by $16 \%$ in 2025 (range 15-18\%), 25\% in 2030 (range $22-28 \%$ ) and $35 \%$ in 2035 (range 31-39\%), compared to business as usual. electricity savings in three chemical subsectors (ammonia, chlor-alkali and calcium carbide)

As one of the main energy carriers in CCMI, electricity consumption in 2016 doubled in comparison to 2005 , with an average annual growth rate of $8 \%$, which is higher than the growth rate of final energy use $(5 \%)$. The share of electricity in the final energy mix increased from $12 \%$ in 2005 to $15 \%$ in 2016. With accelerating electrification in CCMI, electricity consumption is expected to further increase (IEA, 2013; Yue et al., 2018). Efficient use of electricity by adopting 60 EETs can save 6\% in 2030 (range 5-7\%) and $9 \%$ in 2035 (range 8-10\%) of final energy use of CCMI. Investments in energy efficiency in the chemical industry should focus especially on calcium carbide manufacturing (in particular the calcium carbide furnace), which is expected to deliver around 50\% of the electricity savings among three key chemical subsectors (i.e. ammonia, chlor-alkali and calcium carbide). The chlor-alkali sector produces two major electricity-intensive chemicals, i.e. caustic soda and PVC. Efficient ion-exchange membrane electrolyzer (e.g. oxygen depolarized cathodes membrane electrolyzer, and zero electrode-distance membrane electrolyzer) and dry-process acetylene are key to reducing electricity costs in caustic soda and PVC production, 
respectively. Ammonia manufacturing includes four major processes, i.e. gas generation, shift conversion, gas purification and ammonia synthesis. China's ammonia production is dominated by coal feedstocks, which account for $86 \%$ of total ammonia capacity. The process of gas purification thus has the highest potential for conserving electricity (representing around $30 \%$ of total electricity savings in China's ammonia sector), which can be achieved by implementing high-efficiency desulfurization and decarbonization technologies (e.g. pressure swing adsorption for removing $\mathrm{CO}_{2}$ ). Replacing and upgrading low efficiency ammonia synthesis towers can further release around $27 \%$ of the electricity-saving potential. Considering the electricity performance of each process, policy-makers and managers are suggested to scale up efficiency by targeting key areas within an industrial sector. This presents an option to access significant reductions in a rapid way with high cost performance.

\section{Textile industry}

The textile industry in China is not considered an energy-intensive sector. However, CTI consists of a large number of factories which together consume significant amounts of energy. CTI consumes $2 \%$ and $4 \%$ of China's industrial final energy and electricity consumption, respectively. Final energy use of CTI increased dramatically in the period 2000-2016, with an average annual growth rate of 5\%. Within the energy consumption in CTI, electricity is one of the dominant energy sources, with an increasing share from $23 \%$ in 2000 to $45 \%$ in 2016 (NBS 2017).

However, existing studies mainly focus on carbon emissions (Huang et al., 2017; Lin and Moubarak, 2013, 2014b) and have limited information on electricity savings in CTI. An international comparison of energy efficiency shows the large gap between China $(31 \mathrm{MJ} / \$)$ and USA (11 MJ/\$) in the textile industry (Peng et al., 2015a, b). Lin and Zhao (2016b) found the CTI sector has a 20-33\% available potential to improve energy efficiency. Various energy efficiency opportunities (including available and emerging EETs) in the textile industry have been summarized by LBNL, many of which are cost-effective (Hasanbeigi and Price, 2012, 2015). As a dominant energy carrier, efficient use of electricity can effectively reduce the overall energy consumption and indirect emissions in the sector. Electricity-saving potentials of available technologies for major textile processes (i.e. spinning, weaving and wetting processing) are shown in Fig. 10. Most of the technologies are applied to the electric motor-driven systems (i.e. pumps, fans and compressed air). Thus, promoting efficient motor systems is key to realizing electricity efficiency improvement in CTI (Lin and Zhao, 2016a, b).

Energy consumption in China's textile industry will continue to increase, while the growth rate is expected to slow down due to energy efficiency improvements. Various measures (e.g. industrial scale adjustment and technology upgrading) reduce energy use in CTI, of which technology upgrading is the most effective way (Lin and Zhao, 2016a; Wang et al., 2017). It is worth noting that the energy efficiency of the entire motor-driven systems in the textile industry leaves much room for improvement.

\section{Summary of electricity savings and associated emissions reduction}

In this study we aim to include total industrial electricity demand, including purchased power from the grid as well as self-generated power (e.g. by combined heat and power (CHP) plants). For most literatures, we found that the energy demand data is consistent with this definition; however, not all studies are clear in this regard. In terms of savings potential as share, there is little impact to be expected since this is based on the percentual saving potentials of measures that are applied to total electricity demand. The total development of industrial electricity demand may however be underestimated to a certain extent because of this.

Tables 2 and 3 summarize the saving potentials for final energy and electricity use in China's industry and for the five industrial subsectors. The electricity-saving potentials in China's industry show an increasing trend in the period 2020 and 2040, from 4 to $14 \%$. Within total industry, electricity savings in the CISI sector have the largest contribution, followed by CNFMI, CCMI, CCI and $\mathrm{CPPI}^{3}$ in 2020. The non-ferrous metal sector has the largest

\footnotetext{
${ }^{3}$ CPPI can reduce electricity use at least $2 \mathrm{TWh}$, while future trajectories of electricity savings are unavailable.
} 


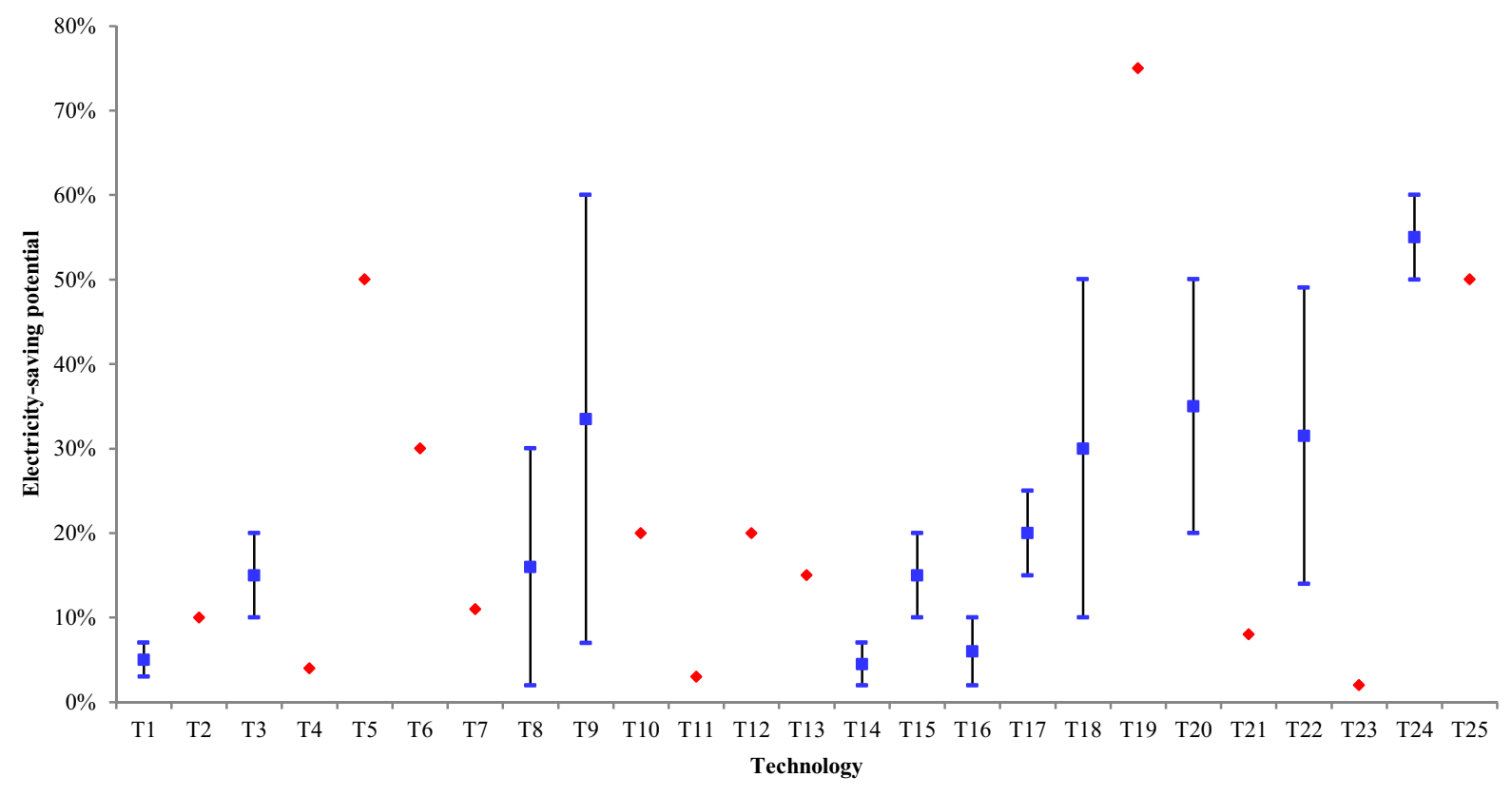

Fig. 10 Electricity-saving potential per technology applied in major textile processes. Note: T1-T25 refer to the technology summarized by Hasanbeigi and Price (2012): No. 3, 7, 12, $16,34,58,97,117,121,127,132,133,134,135,138,139$,

electricity-saving potential with $25 \%$, followed by chemicals (24\%), iron \& steel $(16 \%)$, cement $(8 \%)$ and pulp \& paper (4\%) in 2020. In 2030, the electricity-saving potentials of CISI and CCI increase to $23 \%$ and $15 \%$, respectively. By 2030, the chemical sector $(25 \%)$ still has greater potentials than the iron $\&$ steel and cement sector. In general, CNFMI and CCMI have more opportunities to improve electricity efficiency, while the saving contribution to the whole industry is less than that of the iron \& steel sector.

Based on the data collected in Table 2, co-benefits of electricity savings in terms of emission reduction of GHGs $\left(\mathrm{CO}_{2}, \mathrm{CH}_{4}\right.$ and $\left.\mathrm{N}_{2} \mathrm{O}\right)$ and air pollutants $\left(\mathrm{SO}_{2}, \mathrm{NO}_{\mathrm{x}}\right.$ and $\left.\mathrm{PM}_{2.5}\right)$ in China's industry are calculated (Fig. 11). The emissions of GHGs and air pollutants can potentially reduce by $153 \mathrm{Mt}-\mathrm{CO}_{2 \mathrm{eq}}$ and $699 \mathrm{kt}$ in 2020, and by $1123 \mathrm{Mt}-\mathrm{CO}_{2 \mathrm{eq}}$ and $5137 \mathrm{kt}$ in 2040, respectively. The maximum reduction of $\mathrm{CO}_{2}$, $\mathrm{SO}_{2}$ and $\mathrm{NO}_{\mathrm{x}}$ in 2040 equals $42 \%, 63 \%$ and $68 \%$ in comparison to 2015 industrial indirect emissions, respectively. The emission benefits from electricity savings are important to China for achieving climate
140, 141, 142, 143, 146,153,154, 157 and 158, respectively; the black vertical lines represent ranged potential value from low to high; the blue and red markers mean average value and non-ranged value, respectively

and clean-air goals (e.g. reducing $60-65 \%$ of $\mathrm{CO}_{2}$ intensity by 2030 compared that of 2005).

Discussion of impact modeling factors on results

Sectoral energy/electricity consumption and savings vary quite strongly in the included studies. In order to understand these differences, key factors that impact results are summarized below. These factors are partly based on the results from Sect. 3 that analyzes model approaches and assumptions, recorded in Tables S1, S3, S4 and S5. In addition, a comparison of energy demand levels in baseline scenarios and energy intensity trends, which is included in the Supplementary material, is used.

- System boundary is identified as an important factor that especially has great influence on projections in sectors with multiple products, like non-ferrous metals and the chemical industry. As shown in Fig. S5, final baseline energy use of CNFMI projected by bottom-up approaches developed by Wen and Li (2014) (2.6 EJ) is double that of LBNL (1.3 EJ) in 2020, due to 

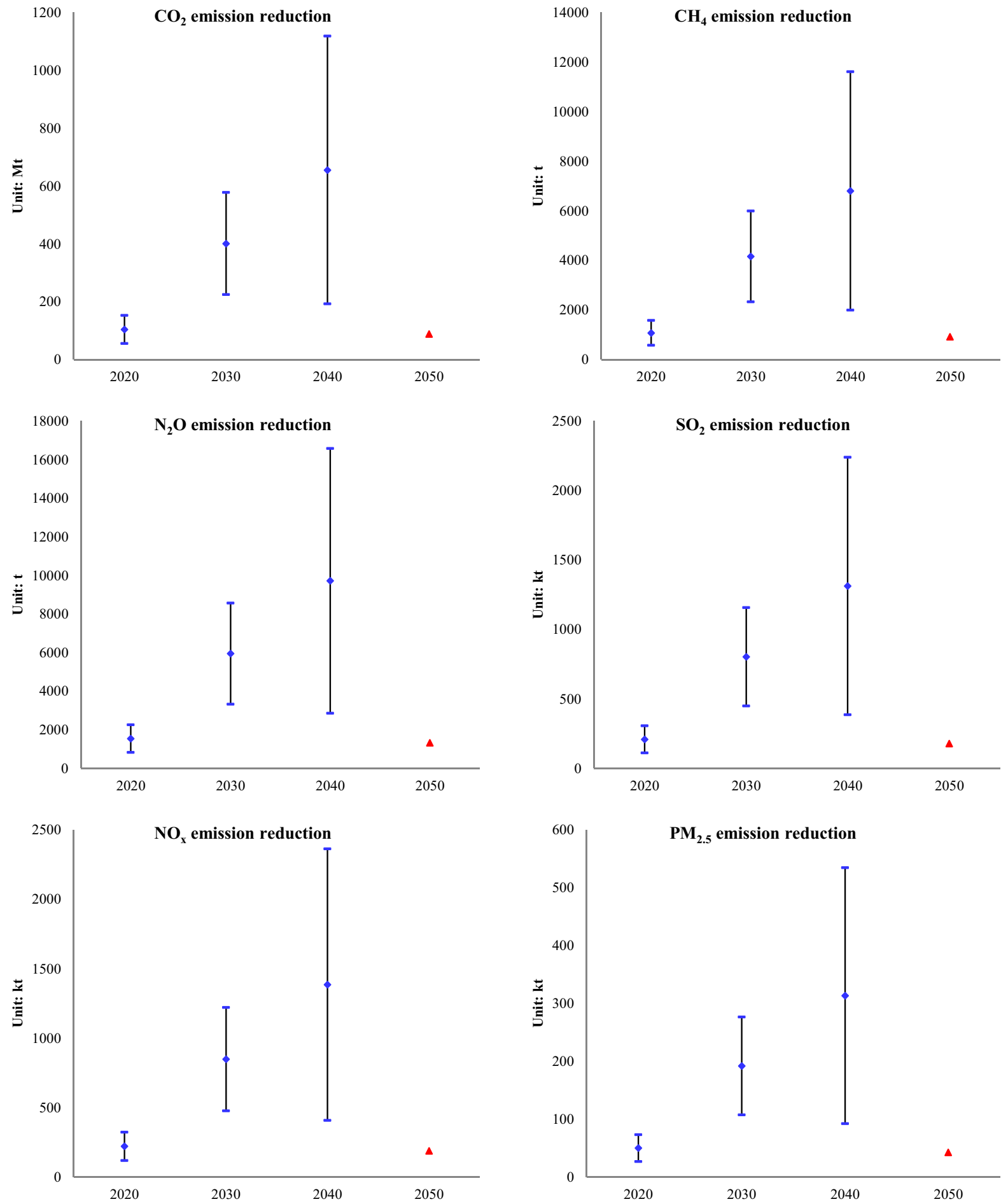

Fig. 11 Emission reduction of GHGs and air pollutants. Note: only THU projected the electricity savings in 2050 for China's industry; the black vertical lines represent ranged emission

value from low to high; the blue and red markers mean average value and non-ranged value, respectively 
differences in the scope of included products (the study of Wen and Li (2014) includes other materials besides aluminum production (e.g. lead, copper and zinc)). Another example is the chemical industry, where a wide range in potentials occurs, from 6 to $20 \%$ in 2020, as shown in Table 2. A main difference in sector coverage concerns which products are included and should therefore always be taken into account when comparing energy-saving potentials. Detailed system boundaries for each study are shown in Table S1.

- The modeling approach is another key factor resulting in significant divergences among projections. Most included top-down approaches focus on modeling short-term horizons (up to 2020), while bottom-up and integrated approaches focus more on the medium and long term (Table 1). Modeling projections by top-down approaches often give bigger energy demand result than other modeling approaches. For example, the studies (Lin \& Wang, 2014b; Lin et al., 2017) using a co-integration model show a much higher energy demand in 2020 for CISI (33 EJ) and CCI (9 EJ) than average levels projected by bottom-up modeling (14 EJ for CISI and 6 EJ for CCI, Supplementary material). This could be related to the higher level of technology detail in bottom-up approaches and assumed lower energy intensity developments. Moreover, there is a larger range in alternative scenario results in terms of energy savings. A key difference among model structures is the drivers used for energy modeling as shown in Table S3 (detailed discussion in Sect. 3) and is related to the next point on socio-economic indicators.

- The assumed development of Social and economic indicators (e.g. GDP (Edelenbosch et al., 2017), population (Zhou et al., 2011) and urbanization (Zhang et al., 2018)) strongly impacts production functions. The modeled output of industrial products in turn directly affects the development of energy demand and thus energy savings for a given sector (Fig. S12). A large level of assumed production (e.g. the found range is 364 to 881 Mt-steel by 2020) usually results in a high energy use in the baseline (ranging from 8 to $17 \mathrm{EJ}$ by 2020). This also impacts the alternative scenarios, together with varying assumptions regarding implemented energy efficiency technol- ogies and policy measures, as indicated in the next point.

- Assumed efficiency improvement room and technology characterization largely determine the modeling potentials of energy savings. Differing collected levels of energy-saving technology impact bottom-up approaches with rich technology representations (as described in Sect. 3 and Table S5). Technology cost is a main barrier for measures when considering necessary investment. High levels of assumed policy instruments (e.g. carbon tax, technology subsidies) can reduce the relative cost of technologies and thus increase the technology implementation level (Li et al., 2017; Zhang et al., 2018). This level is also referred to as the technology diffusion rate and has a direct impact on the saving potential. For example, scenarios modeled by Liu et al. (2017), who included 23 technologies with all nearly $100 \%$ implementation rates in 2030 for CCI, show a higher potential energy savings (relative savings of 20\%) than other studies (e.g. 9-16\% projected by Zhang et al. (2015b)), which included more technologies, but with a lower diffusion rate. Key differences in included policy measures found are the technology representation and the level of economy regulatory incentives.

- Data sources also affect the modeling results to a certain extent. For example, the energy demand for CISI projected by Wang et al. (2007) and LBNL are lower than for other studies, probably because the energy service demands are based on historical data up to 2005. Different data sources and statistical methods used have different qualities and timeliness. The impact of data sources is difficult to quantify, but for long-term trends the impact on sectoral energy use and intensity seems to be limited (Supplementary material).

The absolute development of energy or electricity use in the scenarios and therefore absolute savings are difficult to compare among studies, e.g. due to different activity levels assumed (e.g. more or less iron and steel production). Therefore, the focus was on percentual changes of the alternative scenario compared to the baseline scenario, with the only difference being the implementation of energy efficiency measures, while activity data in the scenarios remain the same. There may however already be some energy efficiency 
improvement included in the baseline scenario, such as is to be expected in real life (e.g. the energy intensity in $\mathrm{GJ} / \mathrm{t}$-steel in most included studies is lower in the end year compared to the base year, see Supplementary material). The potentials are then an underestimation of the energy efficiency improvement compared to base year energy efficiency levels. On the other hand, for quite some studies the base year is 2010 or before, and it is to be expected that the energy intensity has improved in the current situation. However, the actual decrease in intensity, since the base year, may be higher or lower than assumed in the baseline scenario. As another factor, in most studies new and emerging technologies are not included in the energy efficiency potentials, meaning that more potential would be available in the future when these technologies become commercial. Therefore, the potentials should be seen as broad indications and would likely be expanded by new and emerging technologies.

\section{Conclusions}

Industry is the largest energy using sector in China, resulting in high emissions of GHGs and air pollutants, while large potentials for improving energy efficiency exist. With accelerating end-use electrification, coalintensive electricity has become a dominant energy source in China's industry. This systematic review evaluates energy-saving potentials in China's industry, while especially focusing on electricity savings in five industrial electricity users (representing more than 50\% of total industrial electricity consumption) that are generally targeted by the IEA and the Chinese government. Results show varying levels of electricity-saving potentials, depending on sector, modeling approach (e.g. top-down, bottom-up) and scope (included products). Based on the results, synergies of electricity saving and climate change and air quality are quantified. Countries (e.g. India, Poland, Czechia and Australia) structured with heavy industry and coal-based power would get large benefits through saving electricity in end-use sectors. Main conclusions are as follows:

(1) As a key energy carrier, electricity accounts for $\mathbf{2 4 \%}$ of final energy use in China's industry. Electricity consumed by industry increased more than fourfold from 907 TWh in 2000 (16\% of final energy use) to $4003 \mathrm{TWh}$ in 2016 (24\% of final energy use). Coal-intensive electricity results in serious environmental problems, i.e. $45 \%$ of $\mathrm{CO}_{2}, 25 \%$ of $\mathrm{SO}_{2}, 34 \%$ of $\mathrm{NO}_{\mathrm{x}}$ and $14 \%$ of PM emissions of the industry can be attributed to electricity consumption.

(2) China's industrial energy system is shifting to higher power and lower fossil fuels. The share of electricity in final energy use is expected to further increase to $33 \%$ (21-39\%) by 2040 . Electricity-saving potentials, in China's industry, are expected to amount to $4 \%$ (2-5\%), 10\% (6-15\%) and $14 \%(7-24 \%)$ of baseline electricity use in 2020, 2030 and 2040, respectively. The electricity savings contribute to $31 \%$ (23-39\%), $26 \%$ (20-29\%) and $25 \%(11-33 \%)$ of total industrial final energy saving in 2020, 2030 and 2040, respectively.

(3) Electricity-saving potentials (\%) and contributions (TWh) vary for different industrial subsectors. The iron \& steel sector (93 TWh) contributes to the largest electricity savings, followed by non-ferrous metals, chemical, cement and pulp \& paper sector. The nonferrous $(25 \%)$ and chemical sector (24\%) have the largest potentials to save electricity in 2020 . In addition, motor-driven systems in the textile industry leave much room for improving energy efficiency.

(4) Increasing energy efficiency in industry can generate synergies to mitigate climate change and improve air quality by reducing emissions of GHGs and air pollutants. In 2040, the potential co-benefits achieved with saving electricity in industry can be reduced emissions of 192-1118 $\mathrm{Mt}-\mathrm{CO}_{2}, \quad 1995-11,603 \quad \mathrm{t}-\mathrm{CH}_{4}, \quad 2851-16,584$ $\mathrm{t}-\mathrm{N}_{2} \mathrm{O}, 385-2241 \mathrm{kt}-\mathrm{SO}_{2}, 406-2362 \mathrm{kt}-\mathrm{NO}_{\mathrm{x}}$ and 92-534 kt-PM 2.5 . Many options exist to reduce emissions from power generation (e.g. more efficient technology, fuel substitution and end-of-pipe measures), but end-use energy efficiency promotion is often cost-effective and can achieve multiple national energy and environmental goals.

\section{Policy implications and directions for research}

A trend towards higher electricity and lower fossil fuels is observed in China's industrial energy system. The 
efficient use of electricity can contribute to around $30 \%$ of total industrial final energy savings in China. This study shows that promoting electricity savings in specific end-use sectors is a win-win strategy for demandside management and supply-side structural reform. The decrease of electricity demand could reduce emissions of GHGs and air pollutants while limiting the need for construction of new capacity (Peng et al., 2018). Based on the reviewed analysis and discussion, this study highlights the following policy implications (from national, sectoral and regional levels, respectively) and directions for future research.

(1) As for national government, it is strongly suggested to further implement energy conservation and emission reduction through a joint policy of enhancing environment quality and energy efficiency on both demand and supply sides. Electricity savings provide a large potential reduction of air pollutant and GHG emission and need to be included in air quality and climate policy. In addition, policies integrating demand-side savings into power sector planning would help to design a pathway to phase out small and old coalfired units (e.g. $<300 \mathrm{MWh}$ and $>20$ years) with super-polluting (Tong et al., 2018). To economically achieve the sustainable development goals, a cost-effective technology roadmap for industry should be designed, including details on the energy-intensive subsectors, to maximize benefits of electricity savings, emission reduction and improving public health. These benefits outweigh investments. The findings suggest that energy efficiency technology will help policies for climate and air quality to be more cost-effective.

(2) Promoting electricity conservation in different end-use sectors is an important policy measure. Within industry, policies should prioritize the iron \& steel industry with the largest electricity-saving contribution (around 93 TWh in 2020), followed by non-ferrous metals (80 TWh), chemicals (69 TWh) and cement (15 TWh). When implementing sectoral efficiency policies, it would be more effective and economical if decision-makers are able to allocate limited resources to key areas. For example, the efforts for the non-ferrous metals should focus on, e.g. aluminum electrolysis (which consume more than $70 \%$ of electricity use in CNFMI) and motor-driven systems for textiles. It is worth noting that increasing waste material recovery and recycling for non-ferrous metals and pulp $\&$ paper also helps to reduce electricity use but is limited by the available resources. Learning from experiences in the European Union, standardized recycling systems of waste resources (for example, managing the waste material classification and investing in new recycling capacity) should be established to increase the recycling rates of waste materials. Furthermore, new policy of value-added-tax rebates should be formulated to incentive the enthusiasm of enterprises to participate in waste resource recovering and recycling.

(3) The impacts of regional grid distribution to address air pollution (Yang et al., 2013a; Yue et al., 2018) and climate change (Peng et al., 2018; Wang and Zhao, 2017) should not be ignored. This study suggests that regional decision-makers need to not only understand the co-benefits of emission reduction and public health, but also different levels of power supply (and consumption) and air quality related to the possible relocation of electricity-intensive industry. Strict regional standards for large electricity consumers (e.g. aluminum and chlor-alkali sectors) should be carried out to restrict new capacity and phase out inefficient capacity in regions with higher emissions of power generation (e.g. Northeast and North grids). Meanwhile, regions in grids with lower emissions of power generation (e.g. Northwest grids) may consider expanding industrial capacity. Regional development policies should include these priorities to effectively address air quality improvements.

(4) Regional governments should understand gridspecific synergies related to the regional allocation of abatement targets. Synergies between electricity savings and emission reduction vary per region due to the different levels of power use and specific emission intensities. To achieve national reduction goals effectively, this study suggests that different responsibilities should be assumed by different regions. Therefore, specific policies should be designed to set regional targets. Regions in grids with high potentials of electricity savings and emission reduction should bear the largest responsibility; the mini- 
mum burden should be allocated to regions in grids with lower multiple benefits.

(5) Future research should focus on studying electricity-saving trajectories in the non-ferrous metals, textile and pulp \& paper sectors, for which few studies are available. Furthermore, expanding the analysis to other electricity consuming sectors and to provincial/regional level will help to fully understand the contribution of electricity saving to environment and public health, as well as the impacts on grid distribution. Moreover, determining savings helps to identify options to reduce and optimize investments in new power plants and grid expansion, resulting in additional economic benefits. Quantifying the linkages between the supply and demand sides would warrant further research to optimally assess the impacts on power system.

(6) Model-based scenario analysis is expected to continue to play a key role in assessing energy systems. A spread in modeling results for different policy scenarios (e.g. energy efficiency, pollutant control and tax measures) is unavoidable due to differing assumptions for urbanization and industrial electrification (especially in developing countries like China and India). Therefore, it is necessary to further improve modeling structures, upgrade key drivers (e.g. GDP, population and urbanization) and technology representations (e.g. specific technology) to design more effective policies.

\begin{abstract}
Acknowledgements We would like to thank Prof. Sheng Zhou (Institute of Energy, Environment and Economy at Tsinghua University) and Prof. Qi Zhang (SEPA Key Lab on Ecoindustry at Northeastern University) for the valuable comments and input data. The authors gratefully acknowledge Kangyin Dong (School of Business Administration at China University of Petroleum-Beijing), Nan Li (Institute of Nuclear and New Technology at Tsinghua University), Runying An (Center for Energy and Environmental Policy Research at Beijing Institute of Technology), Xuewei Liu (State Key Laboratory of Pollution Control and Resource Reuse at Nanjing University) for the data input in various sectors to this study.
\end{abstract}

Funding This study was supported by the China Scholarship Council (Grant No. 201607040082) and the Natural Science Foundation of China (71904007).

\section{Declarations}

Conflict of interest The authors declare no competing interests.
Open Access This article is licensed under a Creative Commons Attribution 4.0 International License, which permits use, sharing, adaptation, distribution and reproduction in any medium or format, as long as you give appropriate credit to the original author(s) and the source, provide a link to the Creative Commons licence, and indicate if changes were made. The images or other third party material in this article are included in the article's Creative Commons licence, unless indicated otherwise in a credit line to the material. If material is not included in the article's Creative Commons licence and your intended use is not permitted by statutory regulation or exceeds the permitted use, you will need to obtain permission directly from the copyright holder. To view a copy of this licence, visit http://creativecommons.org/licenses/by/4.0/.

\section{References}

Abel, D. W., Holloway, T., Martínez-Santos, J., Harkey, M., Tao, M., Kubes, C., et al. (2019). Air quality-related health benefits of energy efficiency in the United States. Environmental Science \& Technology, 53(7), 3987-3998.

An, R., Yu, B., Li, R., \& Wei, Y. (2018). Potential of energy savings and $\mathrm{CO}_{2}$ emission reduction in China's iron and steel industry. Applied Energy, 226, 862-880.

CEADs. (2017). Sectoral $\mathrm{CO}_{2}$ emission inventory at national level. China Emission Accounts \& Datasets (CEADs). http://www.ceads.net/data/. Accessed 10 February 2020.

Chen, W., Yin, X., \& Ma, D. (2014). A bottom-up analysis of China's iron and steel industrial energy consumption and $\mathrm{CO}_{2}$ emissions. Applied Energy, 136, 1174-1183.

CNMIA (China Nonferrous Metals Industry Association). . (2017). The yearbook of nonferrous metals industry of China. China Nonferrous Metals Industry Association Press.

CTAPI (China Technical Association of Paper Industry). (2018). Almanac of China paper industry 2018. Beijing (China): China Light Industry Press

Dai, Y., Xiong, W., \& Jiao, J. (2013). Roadmap study on achieving technical energy conservation potential in China's industrial sector by 2020. China Science and Technology Press.

Edelenbosch, O. Y., Kermeli, K., Crijns-Graus, W., Worrell, E., Bibas, R., Fais, B., et al. (2017). Comparing projections of industrial energy demand and greenhouse gas emissions in long-term energy models. Energy, 122, 701-710.

EIA. (2018). International energy outlook 2018. Washington, DC (USA): U.S. Energy Information Administration.

Fleiter, T., Fehrenbach, D., Worrell, E., \& Eichhammer, W. (2012). Energy efficiency in the German pulp and paper industry - A model-based assessment of saving potentials. Energy, 40(1), 84-99.

Gao, F., Nie, Z., Wang, Z., Li, H., Gong, X., \& Zuo, T. (2009). Greenhouse gas emissions and reduction potential of primary aluminum production in China. Science in China Series e: Technological Sciences, 52(8), 2161-2166.

Gao, M., Beig, G., Song, S., Zhang, H., Hu, J., Ying, Q., et al. (2018). The impact of power generation emissions on ambient $\mathrm{PM}_{2.5}$ pollution and human health in China and India. Environment International, 121, 250-259. 
Hackl, R., \& Harvey, S. (2013). Applying exergy and total site analysis for targeting refrigeration shaft power in industrial clusters. Energy, 55, 5-14.

Han, Y., Geng, Z., Zhu, Q., \& Qu, Y. (2015). Energy efficiency analysis method based on fuzzy DEA crossmodel for ethylene production systems in chemical industry. Energy, 83, 685-695.

Hao, H., Geng, Y., \& Hang, W. (2016). GHG emissions from primary aluminum production in China: Regional disparity and policy implications. Applied Energy, 166, 264-272.

Hasanbeigi, A., Morrow, W., Masanet, E., Sathaye, J., \& Xu, T. (2013). Energy efficiency improvement and $\mathrm{CO}_{2}$ emission reduction opportunities in the cement industry in China. Energy Policy, 57, 287-297.

Hasanbeigi, A., Morrow, W., Sathaye, J., Masanet, E., \& Xu, T. (2013). A bottom-up model to estimate the energy efficiency improvement and $\mathrm{CO}_{2}$ emission reduction potentials in the Chinese iron and steel industry. Energy, 50, 315-325.

Hasanbeigi, A., \& Price, L. (2015). A technical review of emerging technologies for energy and water efficiency and pollution reduction in the textile industry. Journal of Cleaner Production, 95, 30-44.

Hasanbeigi, A., \& Price, L. (2012). A review of energy use and energy efficiency technologies for the textile industry. Renewable and Sustainable Energy Reviews, 16(6), 3648-3665.

Hasanbeigi, A., Price, L., \& Lin, E. (2012). Emerging energy-efficiency and $\mathrm{CO}_{2}$ emission-reduction technologies for cement and concrete production: A technical review. Renewable and Sustainable Energy Reviews, 16(8), 6220-6238.

He, K., \& Wang, L. (2017). A review of energy use and energy-efficient technologies for the iron and steel industry. Renewable and Sustainable Energy Reviews, 70, 1022-1039.

Huang, B., Zhao, J., Geng, Y., Tian, Y., \& Jiang, P. (2017). Energy-related GHG emissions of the textile industry in China. Resources, Conservation \& Recycling, 119, 69-77.

Huang, J., Pan, X., Guo, X., \& Li, G. (2018). Health impact of China's Air Pollution Prevention and Control Action Plan: An analysis of national air quality monitoring and mortality data. The Lancet Planetary Health, 2(7), e313-e323.

IEA. (2018). World energy balances (2018 edition). Paris (France): International Energy Agency (IEA).

IEA. (2017). Energy technology perspectives 2017: Catalysing energy technology transformation. Paris (France): International Energy Agency (IEA).

IEA. (2016a). World energy outlook 2016. Paris (France): International Energy Agency (IEA).

IEA. (2016b). World energy outlook special report 2016: Energy and air pollution. Paris (France): International Energy Agency (IEA).

IEA. (2013). Technology roadmap: Energy and GHG reductions in the chemical industry via catalytic processes. Paris (France): International Energy Agency (IEA).

IRENA. (2017). Synergies between renewable energy and energy efficiency, a working paper based on REmap.
Abu Dhabi (UAE): International Renewable Energy Agency (IRENA).

Kahrl, F., Li, Y., Su, Y., Tennigkeit, T., Wilkes, A., \& Xu, J. (2010). Greenhouse gas emissions from nitrogen fertilizer use in China. Environmental Science \& Policy, 13(8), 688-694.

Karali, N., Shah, N., Park, W.Y., Khanna, N., Ding, C., Lin, J., et al. (2020). Improving the energy efficiency of room air conditioners in China: Costs and benefits. Applied Energy, 258, 114023.

Karali, N., Xu, T., \& Sathaye, J. (2016). Developing long-term strategies to reduce energy use and $\mathrm{CO}_{2}$ emissions -analysis of three mitigation scenarios for iron and steel production in China. Mitigation and Adaptation Strategies for Global Change, 21(5), 699-719.

Karali, N., Xu, T., \& Sathaye, J. (2012). Industrial sector energy efficiency modeling (ISEEM) framework Documentation. Lawrence Berkeley National Laboratory. https://eta-publications.lbl.gov/sites/default/files/iseem framework_final_lbnl-6078e.pdf. Accessed 10 February 2020.

Ke, J., Zheng, N., Fridley, D., Price, L., \& Zhou, N. (2012). Potential energy savings and $\mathrm{CO}_{2}$ emissions reduction of China's cement industry. Energy Policy, 45, 739-751.

Kermeli, K., ter Weer, P., Crijns-Graus, W., \& Worrell, E. (2015). Energy efficiency improvement and GHG abatement in the global production of primary aluminium. Energy Efficiency, 8(4), 629-666.

Khanna, N., Fridley, D., Zhou, N., Karali, N., Zhang, J., \& Feng, W. (2019). Energy and $\mathrm{CO}_{2}$ implications of decarbonization strategies for China beyond efficiency: Modeling 2050 maximum renewable resources and accelerated electrification impacts. Applied Energy, 242, 12-26.

Klemeš, J. J., Varbanov, P. S., Walmsley, T. G., \& Jia, X. (2018). New directions in the implementation of Pinch Methodology (PM). Renewable and Sustainable Energy Reviews, 98, 439-468.

Kong, L., Hasanbeigi, A., \& Price, L. (2012). Emerging energy-efficiency and greenhouse gas mitigation technologies for the pulp and paper industry. Lawrence Berkeley National Laboratory. https://eta-publications.lbl.gov/ sites/default/files/lbl-5956e-pulp-and-paperrev-dec-2012. pdf. Accessed 10 February 2020.

Kong, L., Hasanbeigi, A., Price, L., \& Liu, H. (2017). Energy conservation and $\mathrm{CO}_{2}$ mitigation potentials in the Chinese pulp and paper industry. Resources, Conservation \& Recycling, 117, 74-84.

Kong, L., Price, L., Hasanbeigi, A., Liu, H., \& Li, J. (2013). Potential for reducing paper mill energy use and carbon dioxide emissions through plant-wide energy audits: A case study in China. Applied Energy, 102, 1334-1342.

Li, C., Zhu, L., \& Fleiter, T. (2014). Energy efficiency potentials in the chlor-alkali sector-A case study of Shandong province in China. Energy \& Environment, 25(34), 661-686.

Li, N., Ma, D., \& Chen, W. (2017). Quantifying the impacts of decarbonisation in China's cement sector: A perspective from an integrated assessment approach. Applied Energy, $185,1840-1848$. 
Li, Y., \& Zhu, L. (2014). Cost of energy saving and $\mathrm{CO}_{2}$ emissions reduction in China's iron and steel sector. Applied Energy, 130, 603-616.

Lin, B., \& Long, H. (2016). Emissions reduction in China' s chemical industry-Based on LMDI. Renewable and Sustainable Energy Reviews, 53, 1348-1355.

Lin, B., \& Long, H. (2015). A stochastic frontier analysis of energy efficiency of China's chemical industry. Journal of Cleaner Production, 87, 235-244.

Lin, B., \& Long, H. (2014). How to promote energy conservation in China's chemical industry. Energy Policy, 73, 93-102.

Lin, B., \& Moubarak, M. (2014a). Estimation of energy saving potential in China's paper industry. Energy, 65, $182-189$.

Lin, B., \& Moubarak, M. (2014b). Mitigation potential of carbon dioxide emissions in the Chinese textile industry. Applied Energy, 113, 781-787.

Lin, B., \& Moubarak, M. (2013). Decomposition analysis: Change of carbon dioxide emissions in the Chinese textile industry. Renewable and Sustainable Energy Reviews, 26, 389-396.

Lin, B., \& Wang, X. (2014a). Exploring energy efficiency in China's iron and steel industry: A stochastic frontier approach. Energy Policy, 72, 87-96.

Lin, B., \& Wang, X. (2014b). Promoting energy conservation in China's iron \& steel sector. Energy, 73, 465-474.

Lin, B., Wu, Y., \& Zhang, L. (2011). Estimates of the potential for energy conservation in the Chinese steel industry. Energy Policy, 39(6), 3680-3689.

Lin, B., \& Xu, L. (2015). Energy conservation of electrolytic aluminum industry in China. Renewable and Sustainable Energy Reviews, 43, 676-686.

Lin, B., \& Zhang, G. (2013). Estimates of electricity saving potential in Chinese nonferrous metals industry. Energy Policy, 60, 558-568.

Lin, B., Zhang, L., \& Wu, Y. (2012). Evaluation of electricity saving potential in China's chemical industry based on cointegration. Energy Policy, 44, 320-330.

Lin, B., Zhang, Z., \& Ge, F. (2017). Energy conservation in China's cement industry. Sustainability, 9(4), 668.

Lin, B., \& Zhao, H. (2016a). Technological progress and energy rebound effect in China's textile industry: Evidence and policy implications. Renewable and Sustainable Energy Reviews, 60, 173-181.

Lin, B., \& Zhao, H. (2016b). Technology gap and regional energy efficiency in China's textile industry: A non-parametric meta-frontier approach. Journal of Cleaner Production, 137, 21-28.

Lin, B., \& Zheng, Q. (2017). Energy efficiency evolution of China's paper industry. Journal of Cleaner Production, 140, 1105-1117.

Liu, X., Zhu, B., Zhou, W., Hu, S., Chen, D., \& Griffy-Brown, C. (2011). $\mathrm{CO}_{2}$ emissions in calcium carbide industry: An analysis of China's mitigation potential. International Journal of Greenhouse Gas Control, 5(5), 1240-1249.

Liu, X., Yuan, Z., Xu, Y., \& Jiang, S. (2017). Greening cement in China: A cost-effective roadmap. Applied Energy, 189, 233-244.

Ma, D., Chen, W., \& Xu, T. (2015a). Quantify the energy and environmental benefits of implementing energy-efficiency measures in China's iron and steel production. Future Cities and Environment, 1(1), 7.

Ma, D., Chen, W., Yin, X., \& Wang, L. (2016). Quantifying the co-benefits of decarbonisation in China's steel sector: An integrated assessment approach. Applied Energy, 162, 1225-1237.

Ma, D., Hasanbeigi, A., \& Chen, W. (2015b). Energy-efficiency and air-pollutant emissions-reduction opportunities for the ammonia industry in China. Lawrence Berkeley National Laboratory. https://eta-publications.lbl.gov/ sites/default/files/lbnl-183064.pdf. Accessed 10 February 2020.

Meng, F. Y., Zhou, D. Q., Zhou, P., \& Bai, Y. (2014). Sectoral comparison of electricity-saving potentials in China: An analysis based on provincial input-output tables. Energy, $72,772-782$.

MEP (Ministry of Environmental Protection of China), \& AQSIQ (General Administration of Quality Supervision, Inspection and Quarantine of China). (2019). Emission standards of air pollutants from stationary sources. http:// www.mee.gov.cn/ywgz/fgbz/bz/bzwb/dqhjbh/dqgdw rywrwpfbz/. Accessed 10 February 2020.

MEP (Ministry of Environmental Protection of China), \& AQSIQ (General Administration of Quality Supervision, Inspection and Quarantine of China). (2016). Ambient air quality standards (GB 3095-2012). http://www.mee. gov.cn/ywgz/fgbz/bz/bzwb/dqhjbh/dqhjzlbz/. Accessed 10 February 2020.

MIIT (Ministry of Industry and Information Technology of China). (2012). Advanced technologies guideline for energy conservation and emission reduction in China's light industry. http://www.miit.gov.cn/n1146285/n1146 352/n3054355/n3057542/n3057546/c3634361/content. html. Accessed 10 February 2020.

MIIT (Ministry of Industry and Information Technology of China). (2017). Action plan 2017-2019 for industrial energy conservation and green standardization. http:// www.miit.gov.cn/n1146295/n1652858/n1652930/n3757 016/c5660058/content.html. Accessed 10 February 2020.

Mischke, P., \& Karlsson, K. B. (2014). Modelling tools to evaluate China's future energy system-A review of the Chinese perspective. Energy, 69, 132-143.

NBS (National Bureau of Statistics of China). (2017). China energy statistical yearbook 2017. China Statistics Press.

NBS (National Bureau of Statistics of China), \& MEP (Ministry of Environmental Protection of China). (2018). China statistical yearbook on environment 2017. China Statistics Press.

NDRC (National Development and Reform Commission of China). (2019). Notice on 2019 tasks for solving overcapacity in key industries. http://www.gov.cn/xinwen/ 2019-05/09/content_5390005.htm. Accessed 10 February 2020.

NDRC (National Development and Reform Commission of China). (2018). National key energy conservation and low carbon technologies promotion catalogue. https:// www.ndrc.gov.cn/fggz/hjyzy/jnhnx/. Accessed 10 February 2020.

NDRC (National Development and Reform Commission of China). (2017). China: 13th Five-Year Plan for power sector. http://www.gov.cn/xinwen/2016-12/22/51515 
49/files/696e98c57ecd49c289968ae2d77ed583.pdf. Accessed 10 February 2020.

Ouyang, X., \& Lin, B. (2015). An analysis of the driving forces of energy-related carbon dioxide emissions in China's industrial sector. Renewable and Sustainable Energy Reviews, 45, 838-849.

Peng, L., Zeng, X., Wang, Y., \& Hong, G. (2015a). Analysis of energy efficiency and carbon dioxide reduction in the Chinese pulp and paper industry. Energy Policy, 80, 65-75.

Peng, L., Zhang, Y., Wang, Y., Zeng, X., Peng, N., \& Yu, A. (2015b). Energy efficiency and influencing factor analysis in the overall Chinese textile industry. Energy, 93, 1222-1229.

Peng, W., Wagner, F., Ramana, M. V., Zhai, H., Small, M. J., Dalin, C., et al. (2018). Managing China's coal power plants to address multiple environmental objectives. Nature Sustainability, 1(11), 693-701.

Rozali, N. E. M., Alwi, S. R. W., Manan, Z. A., Klemeš, J. J., \& Hassan, M. Y. (2014). Optimal sizing of hybrid power systems using power pinch analysis. Journal of Cleaner Production, 71, 158-167.

Rozali, N.E.M., Ho, W.S., Alwi, S.R.W., Manan, Z.A., Klemeš, J.J., \& Cheong, J.S. (2019). Probability-Power Pinch Analysis targeting approach for diesel/biodiesel plant integration into hybrid power systems. Energy, 187, 115913.

Shao, Y. (2017). Analysis of energy savings potential of China's nonferrous metals industry. Resources, Conservation \& Recycling, 117, 25-33.

State Council of China. (2017). China: 13th Five-Year Plan for energy conservation and emission reduction programme. http://www.gov.cn/zhengce/content/2017-01/05/content_ 5156789.htm. Accessed 10 February 2020.

Tong, D., Zhang, Q., Davis, S. J., Liu, F., Zheng, B., Geng, G., et al. (2018). Targeted emission reductions from global super-polluting power plant units. Nature Sustainability, 1(1), 59-68.

U.S. EPA. (2015). Demand-side energy efficiency technical support document. Environmental Protection Agency (EPA), Washington (USA). URL: https://19january2 017snapshot.epa.gov/sites/production/files/2015-11/ documents/tsd-cpp-demand-side-ee.pdf. Accessed 20 September 2020.

Wang, J., \& Zhao, T. (2017). Regional energy-environmental performance and investment strategy for China's non-ferrous metals industry: A non-radial DEA based analysis. Journal of Cleaner Production, 163, 187-201.

Wang, K., Wang, C., Lu, X., \& Chen, J. (2007). Scenario analysis on $\mathrm{CO}_{2}$ emissions reduction potential in China's iron and steel industry. Energy Policy, 35(4), 2320-2335.

Wang, L., Li, Y., He, W., Wang, L., Li, Y., \& He, W. (2017). The energy footprint of China's textile industry: Perspectives from decoupling and decomposition analysis. Energies, 10(10), 1461 .

Wang, M., \& Feng, C. (2018). Decomposing the change in energy consumption in China's nonferrous metal industry: An empirical analysis based on the LMDI method. Renewable and Sustainable Energy Reviews, 82, 2652-2663.
Wen, Z., Chen, M., \& Meng, F. (2015a). Evaluation of energy saving potential in China's cement industry using the Asian-Pacific Integrated Model and the technology promotion policy analysis. Energy Policy, 77, 227-237.

Wen, Z., \& Li, H. (2014). Analysis of potential energy conservation and $\mathrm{CO}_{2}$ emissions reduction in China's nonferrous metals industry from a technology perspective. International Journal of Greenhouse Gas Control, 28, 45-56.

Wen, Z., Meng, F., \& Chen, M. (2014). Estimates of the potential for energy conservation and $\mathrm{CO}_{2}$ emissions mitigation based on Asian-Pacific Integrated Model (AIM): The case of the iron and steel industry in China. Journal of Cleaner Production, 65, 120-130.

Wen, Z., Xu, C., \& Zhang, X. (2015b). Integrated control of emission reductions, energy-saving, and cost-benefit using a multi-objective optimization technique in the pulp and paper industry. Environmental Science \& Technology, 49(6), 3636-3643.

WHO. (2018). Ambient air pollution-A major threat to health and climate. Geneva: World Health Organization (WHO).

Worrell, E., Price, L., Neelis, M., Galitsky, C., \& Zhou, N. (2008). World best practice energy intensity values for selected industrial sectors. Lawrence Berkeley National Laboratory. https://eta-publications.lbl.gov/sites/default/ files/industrial_best_practice_en.pdf. Accessed 10 February 2020.

Wu, X., Zhao, L., Zhang, Y., Zhao, L., Zheng, C., Gao, X., et al. (2016). Cost and potential of energy conservation and collaborative pollutant reduction in the iron and steel industry in China. Applied Energy, 184, 171-183.

$\mathrm{Xu}$, J., \& Fan, Y. (2013). Potential energy saving and $\mathrm{CO}_{2}$ emission reduction in China's cement industry. Progressus Inquisitiones DE Mutatione Climatis, 5, 341-349.

$\mathrm{Xu}$, J., Fleiter, T., Eichhammer, W., \& Fan, Y. (2012). Energy consumption and $\mathrm{CO}_{2}$ emissions in China's cement industry: A perspective from LMDI decomposition analysis. Energy Policy, 50, 821-832.

Yang, X., Teng, F., \& Wang, G. (2013). Incorporating environmental co-benefits into climate policies: A regional study of the cement industry in China. Applied Energy, 112, 1446-1453.

Yang, X., Teng, F., \& Wang, G. (2013). Quantifying co-benefit potentials in the Chinese cement sector during 12th Five Year Plan: An analysis based on marginal abatement cost with monetized environmental effect. Journal of Cleaner Production, 58, 102-111.

Yue, H., Worrell, E., \& Crijns-Graus, W. (2018). Modeling the multiple benefits of electricity savings for emissions reduction on power grid level: A case study of China's chemical industry. Applied Energy, 230, 1603-1632.

Zhang, C., Chen, J., \& Wen, Z. (2012). Assessment of policy alternatives and key technologies for energy conservation and water pollution reduction in China's synthetic ammonia industry. Journal of Cleaner Production, 25, 96-105.

Zhang, C. (2015). Potential analysis and synergy approaches of energy saving and pollution reduction: Case in iron industry. MS thesis. Tsinghua University.

Zhang, Q., Xu, J., Wang, Y., Hasanbeigi, A., Zhang, W., Lu, H., et al. (2018). Comprehensive assessment of energy 
conservation and $\mathrm{CO}_{2}$ emissions mitigation in China's iron and steel industry based on dynamic material flows. Applied Energy, 209, 251-265.

Zhang, Q., Zhao, X., Lu, H., Ni, T., \& Li, Y. (2017). Waste energy recovery and energy efficiency improvement in China's iron and steel industry. Applied Energy, 191, 502-520.

Zhang, S., Worrell, E., \& Crijns-Graus, W. (2015a). Evaluating co-benefits of energy efficiency and air pollution abatement in China's cement industry. Applied Energy, 147, 192-213.

Zhang, S., Worrell, E., \& Crijns-Graus, W. (2015b). Mapping and modeling multiple benefits of energy efficiency and emission mitigation in China's cement industry at the provincial level. Applied Energy, 155, 35-58.

Zhang, S., Worrell, E., \& Crijns-Graus, W. (2015c). Synergy of air pollutants and greenhouse gas emissions of Chinese industries: A critical assessment of energy models. Energy, 93, 2436-2450.

Zhang, S., Worrell, E., Crijns-Graus, W., Krol, M., de Bruine, M., Geng, G., et al. (2016). Modeling energy efficiency to improve air quality and health effects of China's cement industry. Applied Energy, 184, 574-593.

Zhang, S., Worrell, E., Crijns-Graus, W., Wagner, F., \& Cofala, J. (2014). Co-benefits of energy efficiency improvement and air pollution abatement in the Chinese iron and steel industry. Energy, 78, 333-345.

Zhang, S., Xie, Y., Sander, R., Yue, H., \& Shu, Y. (2020). Potentials of energy efficiency improvement and energyemission-health nexus in Jing-Jin-Ji's cement industry. Journal of Cleaner Production, 278, 123335.

Zhang, W., Li, H., Chen, B., Li, Q., Hou, X., \& Zhang, H. (2015d). $\mathrm{CO}_{2}$ emission and mitigation potential estimations of China's primary aluminum industry. Journal of Cleaner Production, 103, 863-872.
Zheng, Q., \& Lin, B. (2017). Industrial polices and improved energy efficiency in China's paper industry. Journal of Cleaner Production, 161, 200-210.

Zhou, N., Fridley, D., McNeil, M., Zheng, N., Ke, J., \& Levine, M. (2011). China's energy and carbon emissions outlook to 2050. Lawrence Berkeley National Laboratory. https:// china.lbl.gov/sites/all/files/lbl-4472e-energy-2050april2011.pdf. Accessed 10 February 2020.

Zhou, N., Khanna, N., Feng, W., Ke, J., \& Levine, M. (2018). Scenarios of energy efficiency and $\mathrm{CO}_{2}$ emissions reduction potential in the buildings sector in China to year 2050. Nature Energy, 3(11), 978-984.

Zhou, S., Wang, Y., Yuan, Z., \& Ou, X. (2018). Peak energy consumption and $\mathrm{CO}_{2}$ emissions in China's industrial sector. Energy Strategy Reviews, 20, 113-123.

Zhou, W. J., Zhu, B., Li, Q. A., Ma, T. J., Hu, S. Y., \& Griffybrown, C. (2010). $\mathrm{CO}_{2}$ emissions and mitigation potential in China's ammonia industry. Energy Policy, 38(7), 3701-3709.

Zhu, B., Chen, X., Zhang, W., Hu, S., \& Jin, Y. (2015). Potential assessment of cleaner production in China's ammonia industry. Journal of Tsinghua University (science and Technology), 54(3), 309-313.

Zhu, B., Zhou, W., Hu, S., Li, Q., Griffy-Brown, C., \& Jin, Y. (2010). $\mathrm{CO}_{2}$ emissions and reduction potential in China's chemical industry. Energy, 35(12), 4663-4670.

Publisher's note Springer Nature remains neutral with regard to jurisdictional claims in published maps and institutional affiliations. 